\title{
La lucha por la vivienda en tiempos de González Videla: Las experiencias de las poblaciones Los Nogales, Lo Zañartu y Luis Emilio Recabarren en Santiago de Chile, 1946-1947
}

\author{
Struggle for housing under González Videla's Government: The experience of \\ Los Nogales, Lo Zañartu and Luis Emilio Recabarren slums in Santiago, \\ Chile, 1946-1947
}

Jorge Rojas Flores*

\begin{abstract}
Resumen: En la coyuntura de 1946-1947, el tema de la vivienda alcanzó alta notoriedad en particular en la ciudad de Santiago, bajo la forma de ocupaciones planificadas de terrenos, que prefiguraron el movimiento de tomas que se reinició en 1957. En este artículo reconstruimos la experiencia particular de tres poblaciones surgidas en medio de un complejo escenario, al inicio de la Guerra Fría, las que dejaron una memoria difusa entre los pobladores involucrados, en gran medida por las características que tuvo el proceso. Nuestro objetivo es entender los patrones comunes que cruzaron estas experiencias, todas las cuales contaron con una activa presencia del Partido Comunista.
\end{abstract}

Palabras clave: Gabriel González Videla, Guerra Fría, Partido Comunista de Chile, vivienda, poblaciones, tomas de terrenos.

\begin{abstract}
In 1946-47, the housing problem reached notoriety in Chile due to squatting. In this article, we analyze the case of three poor urban settlements in Santiago, which emerged in the middle of a complex national and international scenario - at the beginning of the Cold War. The object is to understand the common patterns of this early and underresearched cycle of land occupations, or "tomas," which prefigured the more famous cycle of "tomas" of the midto-late 1950s. We show that these land occupations were led by the Communist Party of Chile, even though this is hardly remembered by the inhabitants nowadays.
\end{abstract}

Keywords: Gabriel González Videla, Cold War, Chilean Communist Party, housing, squatting.

Recibido: 6 julio 2017

Aceptado: 28 septiembre 2017

\footnotetext{
${ }^{*}$ Historiador chileno, académico de la Pontificia Universidad Católica de Chile. Este artículo es producto del Proyecto Fondecyt Regular No 1151302, "La experiencia comunista en el gobierno, 1946-1947. Tensiones y dilemas en los inicios de la Guerra Fría" (2015-2018). El autor agradece el aporte de Laura Baeza en la recopilación de parte de la información, así como los comentarios de un árbitro anónimo que permitieron mejorar la versión definitiva. Correo electrónico: jrojaso@uc.cl.
} 


\section{Introducción}

En un clima político y social cada vez más crispado, preludio de lo que algunos suponían sería la Tercera Guerra Mundial, tres tomas de terrenos, planificadas escrupulosamente, irrumpieron en el escenario chileno, entre 1946 y 1947. En todas ellas, la participación de los comunistas fue central, lo que no pasó inadvertido, porque justamente el Partido Comunista era, por entonces, un actor político clave. A lo largo del gobierno de Alfredo Duhalde (durante gran parte de 1946) había estado en una posición de franca oposición. Tras asumir el gobierno de Gabriel González Videla, en noviembre de 1946, pasó a integrar el primer gabinete, impulsando su programa de reformas y canalizando algunas demandas sociales. Tras la salida de sus tres ministros, en abril de 1947, su influencia no fue menor, ya que hasta agosto conservó varias autoridades, como intendentes y gobernadores. En septiembre, el escenario volvió a cambiar y los comunistas pasaron a la oposición, aunque en un ambiente de polarización creciente, que pronto los llevó a enfrentar la clandestinidad.

De las tres tomas que estudiaremos, una se produjo en Barrancas y terminó con sus protagonistas relocalizados en la chacra Los Nogales, en los alrededores de la Estación Central. La toma de Lo Zañartu, en Ñuñoa, culminó con los participantes en La Legua. Y la de Luis Emilio Recabarren, se desarrolló en Renca y allí se mantuvo. Estas acciones para obtener casa se sumaron a una oleada de movilizaciones, propias de una época especialmente convulsionada.

Al aplicar este estudio de casos, esperamos comprender la vinculación que existió entre estas acciones reivindicativas y la estrategia que desplegó el Partido Comunista (PC) en torno a ellas, así como la intervención de algunas organizaciones sociales (como el Frente Nacional de la Vivienda y algunos de sus asesores) y la respuesta que ofrecieron las autoridades (funcionarios de la Caja de Habitación Popular y del Comisariato, algunos de ellos militares, el Intendente de Santiago, los municipios). A diferencia de otras investigaciones enfocadas en una sola ocupación de terrenos, nos interesa establecer las conexiones que se produjeron en estas acciones, poniendo énfasis en el escenario nacional que acompañó a la toma misma y la participación de distintos actores sociales e institucionales. El estudio que proponemos espera encontrar indicios de lógicas más generales, que permitan hacer comprensible la forma en que se desplegaron las movilizaciones sociales en torno a la vivienda y el peso que tuvo en ellas la acción partidaria, en un temprano contexto de Guerra Fría.

El mayor interés en las investigaciones sobre los pobladores (en disciplinas como la sociología y la historiografía) se ha enfocado en el ciclo que se inició con la conocida toma de La Victoria, en octubre de 1957, y que culminó durante la Unidad Popular. Sobre este período, es posible identificar varios autores centrados en la memoria colectiva, las estrategias de lucha y la intervención del Estado, tanto a nivel de monografías sobre tomas 
particulares como de síntesis más generales y extensas. ${ }^{1}$ Las experiencias previas han sido apenas mencionadas y, cuando alguien lo ha hecho, se ha enfatizado la débil organización que hubo detrás. ${ }^{2}$ Con todo, los acontecimientos han sobrevivido en la memoria colectiva de los propios protagonistas y sus descendientes, aunque con evidentes vacios y contradictorios relatos. Como veremos, en Los Nogales, no hay consenso respecto a si fue toma o no. En el caso de Lo Zañartu, los recuerdos fueron integrados dentro de la trayectoria de La Legua. En la Población Luis Emilio Recabarren la memoria de los acontecimientos ha sobrevido parcialmente y todavía no hay consenso sobre la fecha y el año para conmemorar el aniversario. En los tres casos algunos pobladores reivindican pertenecer a la primera toma en Chile y Sudamérica.

El objetivo de este texto es conocer las formas particulares de organización que surgieron en el movimiento de pobladores que estalló entre 1946 y 1947, identificando específicamente los modos que adoptó la acción colectiva en tres ocupaciones de terrenos, la participación que tuvieron los comunistas y la posible conexión entre ellas.

Como existe una memoria colectiva sobre los tres hitos seleccionados, utilizaremos los recuerdos que sobreviven, confrontando las posibles inconsistencias entre los relatos provenientes de la tradición oral y la documentación de la época. Sobre esto último, hemos revisado varios periódicos que circularon entre 1946 y 1947 (La Nación, La Hora, El Siglo, El Diario Ilustrado, El Imparcial, La Opinión, Habitación, Vivienda y Vivienda Popular, todos de Santiago) y algunos archivos oficiales (de los ministerios del Interior y Justicia, de la Intendencia de Santiago, de la Municipalidad de Ñuñoa). ${ }^{3}$ Debido a que la información encontrada fue abundante, pero fragmentada, y que el proceso mismo de investigación experimentó múltiples reorientaciones, decidimos mostrar con detalle los resultados, para así dejar evidencias del proceso y de los aspectos no resueltos, facilitando el trabajo a futuros especialistas.

\section{La vivienda, Gabriel González Videla y los comunistas}

En la década de 1940, varios sectores coincidían en resaltar el déficit habitacional, que ascendía a más de 200 mil viviendas, lo que resultaba imposible de revertir con la construcción de mil a dos mil viviendas al año por parte de la Caja de Habitación Popular.

\footnotetext{
${ }^{1}$ Sería excesivo citar en detalle a los autores que han investigado a los pobladores (a los que se suman otros tantos relatos testimoniales) porque la lista sería muy extensa. No limitamos a mencionar a Manuel Castells, Vicente Espinoza, Mario Garcés, Manuel Loyola, Ana María Farias Antognini. Boris Cofré Schmeisser, Marcelo Robles Zúñiga, Alexis Cortés Morales, Francisca Calisto, Andrés Budini, Francisco Ripoll, Daniel Fauré y varios más. De algunos de ellos, haremos referencia más adelante.

${ }^{2}$ Vicente Espinoza, Para una historia de los pobres de la ciudad, Santiago, Sur Ediciones, 1988, pp. 229-231 y Mario Garcés, Tomando su sitio. El movimiento de pobladores de Santiago, 1957-1970, Santiago, Lom Ediciones, 2002, pp. 6, 32 y 339.

${ }^{3} \mathrm{Al}$ respecto, tuvimos algunas restricciones con la documentación disponible: el Fondo Intendencia de Santiago del Archivo Nacional únicamente contiene decretos para estos años y la Municipalidad de Renca extrañamente sólo dispone de las actas del consejo municipal de hace un par de décadas.
} 
Esta institución recibió fuertes críticas, además, por no lograr enfocarse en los sectores con menor capacidad de ahorro. ${ }^{4}$

El programa de González Videla contemplaba aspectos polémicos, como una mayor intervención del Estado en el acceso al crédito (creando para ello un Banco del Estado), la nacionalización de los seguros, el petróleo, el gas y la electricidad, la aplicación de una reforma agraria, que incorporara la subdivisión de los latifundios y tierras baldías y su distribución entre sus trabajadores, y el reconocimiento de los sindicatos agrícolas. Otros temas eran más compartidos, como la necesidad de aplicar un plan nacional de construcción de viviendas. ${ }^{5}$ Las diferencias surgían a la hora de identificar el origen de los recursos.

A partir de 1945, el PC adoptó un tono más confrontacional, que se reflejó en las resoluciones del XIII Congreso. El balance sobre el período anterior fue crítico, cuestionándose algunos "errores" que habían llevado a la conciliación de clases y el exceso de tolerancia hacia algunas "irregularidades administrativas". Resumiendo las conclusiones, Ricardo Fonseca planteó: "El Congreso ha resuelto armar al Partido del espíritu más combativo. La voz de orden del Congreso -agregó- es: todos los comunistas al frente de las luchas de la clase obrera y del pueblo, luchando contra los lanzamientos, reponiendo a los lanzados, organizando su defensa de masas [...]". ${ }^{6}$ Esto también se expresó en el énfasis que se dio a la necesidad de participar en el gabinete de la Alianza Democrática, para asegurar el cumplimiento del programa. ${ }^{7}$

Tras el triunfo de González Videla, los comunistas participaron con tres ministros, además de cinco intendentes, 14 gobernadores y varios consejeros de instituciones semifiscales. ${ }^{8}$ En el gobierno, tuvieron varias prioridades: asegurar el abastecimiento (seriamente afectado por la baja producción agrícola, la escasez de divisas y la política de control de precios), incentivar la sindicalización campesina (organizando sindicatos y presentando pliegos de peticiones, con paralizaciones breves), impulsar la reforma agraria (hubo ocupación de algunos predios, a la espera de la expropiación) y acelerar la construcción de viviendas. Para asegurar esto último, los comunistas intentaron tomar la dirección de la Caja de la Habitación Popular, y así transformarla en un agente activo en esa área, con un plan ambicioso que permitiera disminuir el déficit de 350 mil viviendas. ${ }^{9}$ Incluso se rumoreó que

\footnotetext{
${ }^{4}$ Vicente Espinoza, Para una historia de los pobres de la ciudad, Santiago, Ediciones Sur, 1988; Rodrigo Hidalgo, La vivienda social en Chile y la construcción del espacio urbano en el Santiago del siglo XX, Santiago, Instituto de Geografía, Pontificia Universidad de Chile - Centro de Investigaciones Diego Barros Arana, 2005.

${ }^{5}$ El programa aparece transcrito en Ricardo Fonseca, Plan inmediato de gobierno del Partido Comunista. Conferencia Nacional, octubre de 1946, Santiago, Comisión Nacional de Educación, Prensa y Propaganda del Partido Comunista de Chile, 1946, pp.11-14.

${ }^{6}$ El Siglo, 16/dic/1945, p. 5.

${ }^{7}$ El Siglo, 9/dic/1945, p. 7.

${ }^{8}$ Jorge Rojas Flores, "Designación de autoridades en un contexto de Guerra Fría. El caso del gobierno de Gabriel González Videla, 1946-1947”, inédito.

${ }^{9}$ El programa de gobierno no prometía una cantidad en particular. En el mensaje Presidencial de 1947, en una etapa ya tardía, el compromiso era que la Caja construyera 10 mil viviendas sobre un déficit calculado de 350
} 
los comunistas querían su vicepresidente ejecutiva, idea que no prosperó, porque el designado fue el arquitecto José Pistono. ${ }^{10}$

La propuesta técnica de los comunistas (elaborada, entre otros, por la arquitecta Irene Frey) contemplaba un plan de construcción de 50 mil viviendas por año. El texto consideraba la expropiación de predios, para frenar la especulación de precios de sitios; la utilización de materias primas adecuadas a cada zona y el apoyo de los sindicatos de la construcción y de los propios pobladores en la construcción de sus casas, recibiendo los materiales y la asesoría técnica necesarios. ${ }^{11}$ Esta ambiciosa propuesta fue moderada poco después. Ante el gabinete, los ministros comunistas propusieron construir 10 mil viviendas en un año. ${ }^{12}$ En enero de 1947 se agregó una propuesta específica para frenar los lanzamientos. ${ }^{13}$ No era primera vez que planteaban planes de este tipo. El primero se remontaba a 1945 y fue presentado a la Cámara de Diputados. ${ }^{14}$

Mientras los comunistas tuvieron presencia en el gabinete, su estrategia incluyó cierto grado de prudencia, para evitar la ruptura de la frágil alianza que contemplaba a radicales y liberales, con algo de audacia y acciones al límite de lo legal, como el incentivo que se daba a la toma de terrenos, para empujar la reforma agraria, y a la paralización de faenas, sobre todo en el campo, para promover la sindicalización de los obreros agrícolas. Esto último se hizo con el apoyo de algunas autoridades que simpatizaban con la idea de llevar a cabo el programa de gobierno. ${ }^{15}$

La salida de los ministros comunistas en abril de 1947 (tras la elección municipal, donde alcanzaron una notoria alza) debilitó su posición dentro del gobierno, aunque la mantención del resto de las autoridades (intendentes, gobernadores y consejeros) hizo sobrevivir, durante un tiempo, la idea de que seguía siendo un gobierno con participación "tricolor" (radical, liberal y comunista), con un programa por llevar a cabo. Sin embargo, las tensiones surgieron pronto y una de las formas que aplicó el PC para mantener presente el cumplimiento del programa fue reforzar su presencia en los movimientos sociales.

Las instituciones estatales encargadas del tema de la vivienda eran básicamente dos: el Departamento de la Vivienda del Comisariato General de Subsistencias y Precios, que se preocupaba de fiscalizar el valor de los arriendos; y la Caja de Habitación Popular, creada para construir casas baratas y otorgar préstamos (a compradores de sitios y propietarios)

mil. Mensaje, 1947, 294. El PC tenía inicialmente expectativas mayores, reflejadas en la propuesta publicada en octubre de 1946, que indicaba 50 mil viviendas. Fonseca, op. cit., pp. 5-6.

${ }^{10}$ Estanquero, $\mathrm{N}^{\circ} 2,30 /$ nov/1946, p. 8.

${ }^{11}$ El Siglo, 30/nov/1946, p. 5; 6/dic/1946, p. 2.

12 El Siglo, 6/julio/1947, p6. Tras la salida de sus ministros, el PC mantuvo esta propuesta. El Siglo, 8/junio/1947, p. 1.

${ }^{13}$ En la propuesta, impulsada especialmente por el intendente Frías, los lanzamientos judiciales se suspendían cuando se tratara de propiedades requisadas por el Comisariato. El Siglo, 3/enero/1947, p. 2.

${ }^{14}$ El Siglo, 6/julio/1947, p. 6.

15 Jorge Rojas Flores, "Los comunistas en el gobierno de Gabriel González Videla, 1946-1947: estrategias de acción", inédito. 
que permitieran un mayor acceso a la vivienda. Para canalizar las demandas de la población actuaban la Central Nacional de Consumidores y Arrendatarios (CENADECO), la Central de Trabajadores de Chile (CTCH) y principalmente el Frente Nacional de la Vivienda. ${ }^{16}$

El Frente Nacional de la Vivienda llegó a tener mayor intervención en las demandas de acceso a la vivienda. Su origen se remonta a 1933, bajo el nombre de Frente Nacional de Afectos a la Ley 33, que incluía a varias organizaciones de compradores o aspirantes de sitios a plazo. ${ }^{17}$ Se consolidó bajo los gobiernos radicales, pero con ello también surgió la ruptura, a mediados de 1942, entre un sector liderado por comunistas (Augusto Araya Ochoa, Juvenal Gordillo, Francisco Gárate) y otro por socialistas (León Vilarín, Emilio Zapata, José Molina). Para obtener representación en la Caja de la Habitación Popular ambos grupos pretendieron ser la organización legítima. A fines de 1944 el sector de Gordillo logró ser reconocido legalmente. ${ }^{18}$ Con el triunfo de Gabriel González Videla la directiva oficial siguió ganando presencia. Por entonces, sus máximos dirigentes eran Juvenal Gordillo y Alberto Yáñez. Agrupaba a una variada gama de compradores de sitios a plazo, arrendatarios y ocupantes ilegales. Según lo declaraba en junio de 1947, movilizaba a 5 mil familias, unas 15 mil personas, con presencia en diversos comités de vivienda: en el Zanjón de la Aguada (en varios sectores), Mapocho Norte, El Pino, Areneros del Mapocho, Población Sudamérica, La Marquesita, Zañartu, Bolívar, etc. ${ }^{19}$ La composición social era variada, como se puede apreciar: obreros, empleados, cesantes, con distintos niveles de ingreso, que habitaban en conventillos, cités, casas o precarios ranchos (mejoras). Los conflictos también eran múltiples: amenazas de lanzamientos; precios excesivos de arriendo; fraudes en algunos loteos ("loteos brujos"); problemas con la asignación de casas construidas por las cajas de previsión, etc.

\footnotetext{
${ }^{16}$ Como lo aclara Vicente Espinoza, CENADECO se relacionaba con el tema de la vivienda a partir de las funciones que tenía el Comisariato en torno al valor y las condiciones del arriendo; la CTCH fue impulsora de la CENADECO, participaba en la Caja de la Habitación Popular e hizo propuestas globales en políticas de vivienda a los sucesivos gobiernos; y el Frente Nacional de la Vivienda, por su parte, era la organización más especializada en el tema, también tenía presencia en la Caja y agrupaba a los distintos comités de vivienda. Espinoza, op. cit., pp. 121-238.

${ }^{17}$ Inicialmente su Consejo Ejecutivo estaba integrado por representantes de la Confederación de Sociedades Cooperativas de Chile con Población, la Junta Central de Pobladores de Chile, el Comité Único Pro Defensa de la Ley 33 de Compradores de Sitios a Plazos y la Junta Central de Dueños de Mejoras. En una etapa temprana (1933-1934) a través de su periódico Habitación es posible detectar la presencia de trotskistas (por ejemplo, Oscar Waiss, asesor jurídico de la Junta Central de Poblaciones) y también de comunistas y anarquistas, en abierta o más solapada rivalidad. Entre los dirigentes del Frente destacaban Leopoldo González, Alberto Yáñez, Marcial Albornoz y Juan Gacitúa Escobar. Para todo esto nos basamos en varios números de Habitación, el que, a partir de 1936, se transformó en Acción Comunal. También resulta útil el texto de Espinoza, op. cit., pp. 136-184.

${ }^{18}$ El debate sobre el reconocimiento al sector liderado por Gordillo (que el Contralor Agustín Vigorena no respaldó inicialmente) puede verse en el Archivo Nacional - Fondo Ministerio de Justicia, vol. 6228, Decretos 4471-4488, Decreto No 4474, 6/nov/1944 y antecedentes. En 1947, en el Frente disidente se contaban: Manuel Rojas Aranda, José Molina C. y Pedro Cáceres Corvalán (este último, socialista trotskista). El Diario Ilustrado, 22/nov/1946, p. 1; 21/junio/1947, p. 1. La militancia de Cáceres en Humberto Valenzuela, Historia del movimiento obrero chileno, Santiago, Editorial Quimantú, 2008, p. 103.

${ }^{19}$ El Siglo, 22/junio/1947, p. 11.
} 
Entre las estrategias de acción que utilizaron los sectores populares para paliar los problemas de vivienda se encontraba la ocupación ilegal de sitios, sin ser la única. ${ }^{20} \mathrm{~A}$ partir de 1945 esta práctica se hizo cada vez más frecuente. La Población El Pino, en la ribera norte del Río Mapocho (en Las Hornillas, entre Bulnes y Manuel Rodríguez), tuvo amplia cobertura de prensa desde fines de ese año, debido a los anuncios de desalojo. La ocupación se había producido en un momento no precisado, posiblemente durante la guerra, debido a que se corrió la voz de que el sitio estaba abandonado, porque su propietario era un nazi. Cuando comenzaron los preparativos para la construcción de la Población Juan Antonio Ríos, los 1.500 ocupantes ilegales fueron avisados de desalojo. Aunque se les propuso cambiarse hacia San Pablo, los pobladores rechazaron la oferta porque implicaba perder lo que habían construido. Sin embargo, finalmente en diciembre un grupo importante cedió y fue trasladado a Quinta Normal (San Pablo 4.700, frente al Polígono). ${ }^{21}$ Más adelante la nueva ubicación pasó a denominarse Población Manuel A. López. ${ }^{22}$

Otro lugar que concentró la atención fue el Zanjón de la Aguada, por sus complejas condiciones higiénicas, en terrenos que también se utilizaban como basural. Al parecer, los pobladores comenzaron a instalarse allí en 1945 o quizás un poco antes. ${ }^{23}$ El Estado tuvo cierta responsabilidad en eso, porque algunos de sus organismos proponían a las familias sin casa el traslado transitorio a ese sector. Fue lo que sucedió con la Dirección de Auxilio Social, dependiente del Ministerio del Interior, que les planteó ese destino a los pobladores de El Pino, aunque estos lo desecharon. ${ }^{24}$ En 1947 el lugar ya estaba bastante saturado. Los cálculos estimaban que allí había entre 450 y 700 familias, unas 5 mil personas (entre ellos, 1.300 niños). ${ }^{25}$ Desde mayo, a solicitud de la Caja de Habitación Popular, el sector era vigilado por la policía para evitar que llegaran más familias. Los comités del Frente Nacional de la Vivienda tenían presencia en el Zanjón y autorizaban la llegada de nuevos

\footnotetext{
${ }^{20}$ Otras fórmulas utilizadas fueron las huelgas de arrendatarios (como la de 1925), las solicitudes a la Caja de la Habitación Popular, la compra a través de las cajas de previsión y la adquisición a particulares. Las distintas estrategias, a lo largo del siglo, en Espinoza, op. cit.

${ }^{21}$ El propietario del predio era Anselmo Scheer (escrito a veces Scher). Posiblemente el lugar volvió a ser ocupado, porque la Población El Pino siguió apareciendo en el listado de poblaciones callampas de 1949 (de la Dirección del Trabajo). Véase Sara Sepúlveda, Población Callampa. Estudio realizado en la Población Callampa Nueva Matucana, memoria, Escuela de Servicio Social, Universidad de Chile, 1952, cuadro entre pp. 5-6. La resistencia a la reubicación no fue unánime, porque también hubo declaraciones más conciliadoras. Finalmente se impuso el traslado, aunque es posible que un grupo haya permanecido en el lugar. El Siglo, 15/sept/1945, p. 5; 21/sept/1945, p. 7; 19/oct/1945, p. 7; 27/oct/1945, p. 8; 28/oct/1945, p. 11; 29/oct/1945, p6; 2/nov/1945, p. 4; 4/nov/1945, p. 5; 5/nov/1945, p. 1; 7/nov/1945, p. 1; 9/nov/1945, p. 1; 12/nov/1945, p. 7; 14/nov/1947, p. 8; 8/dic/1945, p. 5; 11/dic/1945, p. 7; 13/dic/1945, p. 4; 17/dic/1945, p. 5; 22/dic/1945, p. 10; 31/dic/1945, p. 10. La nueva ubicación también era denominada Lo Acevedo, en referencia a la ex chacra de ese nombre, en Quinta Normal, a la altura de la calle Los Aromos.

${ }^{2}$ El Siglo, 14/nov/1947, p. 8; 15/nov/1947, p. 8. Para entonces, se anunciaba nuevamente el traslado de algunas familias desde la Población Manuel A. López, esta vez a la Población Simón Bolívar.

${ }^{23}$ La estudiante de servicio social Sara Sepúlveda señalaba en 1952 que las primeras poblaciones "callampas" habían surgido diez años antes (¿1942?), siendo las más antiguas las ubicadas en el Zanjón de la Aguada y las de areneros del río Mapocho. Sepúlveda, op. cit., p. 10.

${ }^{24}$ El Siglo, 8/dic/1945, p. 5.

${ }^{25}$ El Siglo, 25/julio/1947, p. 3 y 5; 6/nov/1947, p. 8; 15/nov/1947, p. 8; 16/nov/1947, p. 12.
} 
pobladores. Esto estaba en conocimiento de la autoridad y en un comienzo hubo tolerancia al respecto, hasta que (posiblemente en junio o quizás antes) se notificó al dirigente Manuel Segovia, encargado de otorgar autorizaciones, que ya no se podrían levantar más construcciones. ${ }^{26}$ Por entonces, los técnicos habían confirmado que era inviable construir en ese mismo sector, de suelos blandos e inundables. ${ }^{27}$

Según lo denunciaba, a mediados de 1947, un grupo de pobladores socialistas, el Frente Nacional de la Vivienda liderado por los comunistas había adoptado una estrategia de actuar "a viva fuerza y con engaños", apoderándose o tomando por "asalto" varios sitios o poblaciones. Daba el ejemplo de la ocupación de los terrenos de la Población O’Higgins en la Chacra El Pino; de la Población Rivera, de propiedad de un particular; de la Población General Velásquez, construida por la Caja de la Habitación (en este caso fueron desalojados); y de la Población Anexa Lautaro en Barrancas. ${ }^{28}$

De algunas de ellas tenemos algunos antecedentes. En el caso de la Población O'Higgins, en el paradero 30 de Gran Avenida, el problema se había iniciado aproximadamente en 1945, cuando un grupo de 500 familias llegó a un compromiso de compra con un particular, propietario de un predio, en la antigua Chacra El Pino. Tras pagar una primera cuota (mil pesos de pie), los compradores ocuparon el sitio eriazo, que no contaba siquiera con un pilón de agua. A comienzos de 1947, tras dos años, los dos mil ocupantes alegaban que el propietario seguía sin invertir en los servicios básicos. Para entonces, contaban con el apoyo de algunas autoridades comunistas. Es probable que una parte de los ocupantes no hubiera hecho el pago acordado. ${ }^{29}$ A mediados de 1947 había orden de desalojo, debido al conflicto que tenían con la Caja de Habitación Popular, la que estaba forzando la compra de los sitios a un valor muy bajo, para que abandonaran el lugar. ${ }^{30}$

El caso de la Población General Velásquez, al norte de lo que sería Los Nogales, no parece haber estado ligado al PC, como lo sugería la denuncia socialista. La toma de las casas fue

\footnotetext{
${ }^{26}$ Archivo Nacional - Fondo Ministerio del Interior (en adelante, ANMI), vol. 12341, Oficios 2335-2656, oficio $\mathrm{N}^{\circ} 2566$, 12/junio/1947, del Ministerio del Interior a la Caja de Habitación Popular. Una familia denunció en junio de 1947 que había pagado un monto por su incorporación, pero la policía no le había permitido instalarse. Los dirigentes le aclararon que debían hacerlo de noche, sorteando así la prohibición. La familia no estuvo dispuesto a hacerlo y protestó ante la prensa. El Diario Ilustrado, 20/junio/1947, p. 1 y 4.

${ }^{27}$ El Siglo, 4/junio/1947, p. 1.

${ }^{28}$ También se acusaba al Frente de crearle dificultades a la Caja de la Habitación para construir la Población Juan Antonio Ríos. El Diario Ilustrado, 21/junio/1947, p. 1. Quizás se refería al problema que hubo con la Población El Pino, instalada en el predio donde debía construirse la Población Juan Antonio Ríos. También puede ser una alusión a un conflicto laboral de los obreros de la construcción (gremio en el que los comunistas tenían fuerza) que estaban levantando esa población.

${ }^{29}$ Según los datos que entregó la prensa, el propietario (Luis Contreras Sotomayor) había recibido 60 mil pesos (mil pesos por cada sitio), pero en 1947 el total de familias ocupantes eran 500. El apoyo provino del regidor comunista Moisés Ríos, para lograr acceder al agua, y del Ministro de Obras Públicas, quien comprometió el envío de ingenieros. Véase El Siglo, 2/feb/1947, p. 11.

30 Suponemos que la Caja les prometía la devolución del monto pagado, que fue muy bajo. El Siglo, 22/jul/1947, p. 8.
} 
reportada en enero de 1946 por varios diarios y ninguno hizo esa asociación. ${ }^{31}$ De hecho, El Siglo la calificó de "provocación”. Solidarizó con los ocupantes que sufrieron la represión policial, pero consideró que los pobladores habían sido instigados por un dirigente, ante la desesperación de no ser beneficiados por el sorteo que se aplicó. ${ }^{32}$ El rápido desalojo no dejó mucha huella del hecho.

Algo distinto ocurrió en la ocupación de la Población Pedro Montt. La Caja de Seguro Obrero había asignado y entregado un grupo de casas en noviembre de $1946 .{ }^{33}$ Según lo planteaban los ocupantes, los beneficiados no eran obreros, sino personas elegidas por su afinidad política. Por ello, un grupo ligado al Frente de la Vivienda se tomó las casas. Los desplazados se hicieron representar por una Brigada Carlos Marx, lo que refuerza la sospecha de que detrás de la ocupación hubo una rivalidad política entre socialistas y comunistas. $^{34}$

Otra zona que atrajo a ocupantes ilegales fue la comuna de Ñuñoa, en los alrededores del Estadio Nacional. En su costado oriental, unas 700 familias realizaron sucesivas tomas en 1946, según lo recordaba Juan Araya (por entonces un joven de 20 años), en predios de la Caja del Seguro Obrero. Así nacieron las poblaciones Lo Encalada, con 200 familias; San Eugenio, con 220; San Nicolás, con 120, y otras más, con 100 familias. $^{35}$

La ocupación organizada de terrenos comenzó a extenderse por una confluencia de factores favorables, a partir de 1945, intensificándose en 1946 y 1947. El escaso nivel de construcción de viviendas sociales, a bajo precio, fue aumentando el déficit habitacional año a año. Por otra parte, la migración hacia Santiago siguió creciendo, lo que llevó al

\footnotetext{
${ }^{31}$ El dirigente que lideró la acción, Carlos Roberto Jiménez Huidobro, en su calidad de presidente del Comité de Vecinos, no parece haber estado ligado al Frente Nacional de la Vivienda filocomunista, ni al que dirigían los socialistas. Se le menciona como dirigentes de una Liga de Arrendatarios, aunque no se le atribuye una determinada filiación política. El Mercurio, 29/enero/1946, p. 1; La Nación, 29/enero/1946, p. 9; La Hora, 29/enero/1946, p. 4; Las Noticias de Última Hora, 28/enero/1947, p. 16; El Imparcial, 28/enero/1946, p. 1.

${ }^{32}$ El Siglo, 29/enero/1946, p. 8.

${ }^{33}$ Con ocasión de la entrega de algunas casas de esta población, estuvieron presentes el cardenal Caro, el socialista (trotskista) Carlos Videla (consejero de la Caja de Seguro Obrero) y delegados de las poblaciones Balmaceda, Lo Franco y Lautaro. El presidente de la Junta Directiva de la Población Pedro Montt era José Rojas Escudero, de quien no tenemos referencias. El Diario Ilustrado, 25/nov/1946, p. 16.

${ }^{34}$ El Siglo, 18/junio/1947, p. 8.

${ }_{35}$ El relato de Juan Araya fue publicado en 1972, cuando ya era un reconocido dirigente poblacional comunista. Según este testimonio, esas tomas dieron origen más tarde a la Población Exequiel González Cortés. En Cecilia Urrutia, Historia de las poblaciones callampas, Santiago, Editorial Quimantú, 1972, p. 71. Las ocupaciones ilegales de esta zona sobrevivieron bastantes años porque recién en 1962 unas 500 familias de la "callampa" Lo Encalada fue trasladada a la Población Exequiel González Cortés. Daniel Palma Alvarado, Villa Olímpica, Santiago: apuntes para su historia, inédito, pp. 9-10. Como aclara Palma, la Población Exequiel González Cortés (villas Salvador Cruz Gana y Canadá) a veces es confundida con la Unidad Vecinal Exequiel González Cortés-ex Villa Olímpica, por su cercanía y por haber sido construidas en la misma época. Todo indica que la Población Lo Encalada estaba ubicada cerca de la actual calle homónima, aunque Sara Sepúlveda, en su tesis de 1952, menciona cinco sectores con ese nombre. Sepúlveda, op. cit., cuadro entre pp. 5-6.
} 
levantamiento de chozas precarias en las riberas de canales y ríos, y en predios baldíos, de propiedad municipal, particular o desconocida. La ocupación ilegal de terrenos comenzó a multiplicarse, junto con la proliferación de órdenes judiciales de desalojo, a veces a consecuencia de las tomas, aunque también por la compra irregular de sitios o por decisión de los propietarios que buscaban un destino más rentable a las casas que arrendaban. Durante la campaña electoral de 1946 el tema fue uno de los más sensibles y la candidatura de González Videla se comprometió a ofrecer una solución al respecto, deteniendo los lanzamientos y aumentando la construcción de viviendas de emergencia. Al asumir el nuevo gobierno, los pobladores organizados por el PC se sintieron más respaldados, lo que fortaleció al Frente Nacional de la Vivienda. Un sector que al parecer también estaba ligado a los comunistas creó una Agrupación de Moradores en Predios Fiscales, seguramente para negociar la posibilidad de permanecer en ellos. ${ }^{36}$ El nombramiento de René Frías Ojeda en la intendencia de Santiago agregó un ingrediente coyuntural importante, ya que este joven abogado tomó el reto con especial afán y suspendió el uso de la fuerza para los casos de desalojo, cuando los ocupantes no tenían dónde reubicarse. La salida de los ministros comunistas (con la consiguiente amenaza de incumplimiento del programa) y la acusación judicial contra el intendente volvieron a poner el acento en la movilización de los pobladores, esta vez con el apoyo entusiasta de los comunistas. Esto se manifestó, por ejemplo, en las iniciativas en apoyo al intendente, en junio y julio de 1947. En una manifestación callejera en su honor, varios comités de pobladores desfilaron por el centro, con carros alegóricos. ${ }^{37}$

Aunque las ocupaciones surgieron en una coyuntura común, tuvieron particularidades que es necesario conocer, para apreciarlas en detalle. A los casos ya esbozados agregaremos tres, especialmente importantes: Los Nogales, Lo Zañartu y Luis Emilio Recabarren.

\section{Población Los Nogales}

Los recuerdos del origen de la Población Los Nogales son algo difusos, aunque todos coinciden en que se remonta al 8 de enero de 1947. Algunos recuerdan que se trató de una toma de terrenos, la primera realizada en Chile, mientras otros niegan esta posibilidad y plantean que fue un loteo autorizado por el Estado, y coordinado por el capitán Gálvez. ${ }^{38}$

El relato del viejo dirigente Augusto Vergara, en cambio, concilia las dos versiones, al plantear que hubo una toma organizada de un potrero de propiedad de una viuda, en una fecha no precisa, por parte de 90 familias que provenían de comités de vivienda de la colindante Población Lautaro, en Barrancas. Una vez en el lugar, el intendente habría

\footnotetext{
${ }^{36}$ Entre sus dirigentes estaba Manuel Segovia, que ya vimos (en junio de 1947) otorgando permisos para instalarse en el Zanjón de la Aguada. El detalle de la directiva era el siguiente: Daniel Castañeda, presidente; Sara Morel, secretaria; Luis Mattus, tesorero; Manuel Segovia y Raúl Briones, directores; y Aradio (¿Arcadio?) Romero, secretario de prensa. Las Noticias Gráficas, 8/nov/1947, p. 16.

${ }^{37}$ El Siglo, 17/julio/1947, p. 1.

38 Daniel Fauré y Cristina Moyano (eds.), Memoria social de la población Los Nogales (1947-2015), Santiago, Universidad de Santiago de Chile, 2016, 19-22.
} 
aceptado que no fueran desalojados, dedicándose a buscar un predio fiscal donde poder trasladarlos, con la participación del comité de vivienda. Finalmente se eligió la chacra Los Nogales que pertenecía a la Caja de Seguro Obrero, la que sería vendida a un bajo precio. Aceptada la propuesta, los ocupantes fueron trasladados al lugar en camiones del Ejército un día 8 de enero. ${ }^{39}$

El testimonio escrito de Vergara, un joven de 25 años cuando ocurrieron los hechos, no menciona los nombres de los dirigentes que lideraron la toma. Tampoco lo hace el texto publicado en 2016, sobre la base de relatos orales. El único que lo hace es Ercides Martínez, a partir de conversaciones con antiguos dirigentes, identificando a los integrantes de un Comité Central, todos comunistas: Carlos Lobos, Erasmo Mayorinca y el secretario comunal del PC, que no detalla por su nombre. ${ }^{40}$ En el caso de Mayorinca, por su juventud (tenía 21 años en 1947), podemos suponer que participó más tardíamente como dirigente, cuando los mayores cedieron su lugar a consecuencia de la persecución. ${ }^{41}$

Los diarios de la época aportan información adicional que la tradición oral fue omitiendo, además de precisar los distintos momentos en que se produjeron los hechos. A través de un diario conservador, nos enteramos de que el 17 de noviembre de 1946 hubo un incidente en la Población Anexa Lautaro de Barrancas. Según los afectados, un grupo "asaltó estos terrenos y procedió a levantar algunas casuchas insalubres, para alegar posesión del bien raíz". Los denunciantes alegaban que ellos eran los propietarios del sitio, "modestos trabajadores", quienes lo estaban adquiriendo desde junio a la señora Zenobia Zamudio de Petersen (la viuda que recuerda Vergara). Las cuotas estaban siendo pagadas puntualmente cuando se produjo el "asalto", "un despojo violento", instigado por elementos del Partido Comunista. Se presentó una querella criminal y se colocaron cuidadores en el resto de la propiedad, para precaver una nueva ocupación, pero la situación no mejoró. Días después unos 200 "usurpadores", armados de palos, cuchillos y carabinas, habrían asaltado a un pequeño grupo de pobladores que estaban regularizando el pago de las cuotas, robándoles 10 mil pesos. La idea de los ocupantes era acogerse a la Caja Habitación Popular. El abogado de los denunciantes era el conocido dirigente socialista Óscar Waiss, acompañado de Manuel Cortés Correa, de la misma militancia. ${ }^{42}$ Una versión distinta atribuía la

\footnotetext{
39 Augusto Vergara González, “Cómo nació la idea de la ocupación de terrenos en las poblaciones Lautaro San Pablo, el año 45 al 46, para establecerse definitivamente en Población Los Nogales”, inédito, pp. 1-3, disponible en http://poblacionlosnogales.cl/relatos-nogalinos/. La versión publicada en 1999 es diferente y por ello la citaremos en forma separada. Véase Augusto Vergara González, "Población Los Nogales", en Historia de la población Los Nogales y otros poemas, Santiago, Centro Cultural Taller Literario Los Copihues, 1999, pp. 8-10.

${ }^{40}$ Ercides Martínez, "Enrique Molina Gutiérrez”, en http://elboletinrojo.blogspot.cl/2014/12/enrique-molinagutierrez.html. Martínez nos pudo aclarar personalmente (12/junio/2017) que esta información la obtuvo de varias fuentes, como el propio Enrique Molina y Pedro Cabezas, entre otros.

${ }^{41}$ Erasmo Mayorinca Chávez había nacido en febrero de 1926 (Registro Civil).

42 Óscar Waiss por entonces militaba en el Partido Socialista, aunque años antes había pertenecido al sector comunista que siguió a Manuel Hidalgo y luego se definió como trotskista. El representante de los pobladores era Manuel Cortés Correa. El Diario Ilustrado, 23/nov/1946, p. 4. Meses después el Frente Nacional de la Vivienda socialista volvió a referirse al tema: liderado por comunistas, el grupo había asaltado el terreno,
} 
situación a un "loteo brujo", es decir, irregular y sin autorización, del cual se responsabilizaba al citado Manuel Cortés, regidor y dirigente de los pobladores, quien habría comprado el predio a la viuda de Petersen, a un precio muy bajo, vendiendo a su vez el terreno a militantes de su partido. ${ }^{43}$

Todo lo anterior parece indicar la existencia de un conflicto político entre comunistas y socialistas (posiblemente trotskistas, con presencia entre los pobladores), uno de tantos en esta época, además de acusaciones de fraude. No fue el único que se produjo en Barrancas. Según un informe de Carabineros, de junio de 1947, en las poblaciones San Pablo, Lautaro, Gabriela Mistral y Barrancas, todas de Barrancas, "diferentes personas y de diversas ideologías políticas" habían ocupado terrenos sin tener título. El informe no indica una fecha precisa, pero quizás estas acciones se iniciaron en noviembre, como vimos. Uno de esos grupos, dirigido por Fernando Barahona, estuvo involucrado en algunos incidentes, en marzo, que terminaron con heridos. La policía tuvo que mantener vigilancia durante seis meses la Población Gabriela Mistral, para evitar enfrentamientos entre sus habitantes. La Población San Pablo también quedó bajo vigilancia, por la denuncia que hicieron vecinos de esas población contra Barahona, calificándolo de comunista. ${ }^{44} \mathrm{El}$ ambiente, como se ve, estaba bastante convulsionado. El relato de Augusto Vergara, en cambio, menciona la

\footnotetext{
"levantando en la noche como los bandoleros casuchas, y dejando sin sus sitios a más de 130 familias que son las verdaderas dueñas de ellos". El Diario Ilustrado, 21/junio/1947, p. 1. Una variante de este relato fue publicado en 1949. Lorenzo Órdenes, uno de los pobladores afectados, planteaba por entonces que en abril de 1946 se supo de la venta de un terreno "sobrante" de la Población Lautaro (ex chacra Santa Elisa). Una comisión hizo las averiguaciones, procedió a conversar con la propietaria, logró juntar el pie e hizo todos los trámites legales, quedando finiquitado el negocio el 5 de julio de ese año. Los adquirentes pensaron ocupar el sitio, pero no pudieron hacerlo, debido a que "algunas personas sin darse cuenta que los terrenos eran de nosotros, habían procedido a ocuparlos. En esto [se] nos pasó más de un año y medio [en] que tuvimos numerosas dificultades y un gasto aproximadamente [sic] a los \$300.500.000". Recién fue posible ocuparlos en 1948. La Voz de Barrancas, $\mathrm{N}^{\circ} 2$ [2da quincena/oct./1949], p. 2; N³, 1ra quincena/nov/1949, p. 2.

43 La denuncia se habría producido en las sesiones del 11/dic/1947 y 12/feb/1948 del Consejo de la Municipalidad de Las Barrancas (es decir, mucho después de producidos los hechos), cit. por Ana María Farías Antognini, Urbanización, política de vivienda y pobladores organizados en Las Barrancas: el caso de la Población Neptuno, 1959-1968, Santiago, memoria para optar al grado de Licenciado en Historia, Pontificia Universidad Católica de Chile, 1992, p. 16. Una variante de esta acusación apareció en 1953 y decía que Cortés había obstruido la venta en 1940, transformándose en loteador en 1946. El Siglo, 1/agosto/1953, p.2. Sobre el origen de la Población Lautaro (y la Anexa Lautaro), vinculada estrechamente al Partido Socialista, véase Marcelo Robles Zúñiga, Historia de los pobladores de Las Barrancas. Autonomía, participación política, politización, ideologización, resistencia y desobediencia civil de la organización de los pobladores de Las Barrancas, 1930-1984, Santiago, seminario para optar al grado de Licenciado en Historia y Ciencias Sociales, Universidad Arcis, 2007, pp. 39-44, 72-74, 86-88, 101-102. Algunas referencias más generales en Pudahuel: en el camino de la memoria. De las Barrancas a Pudahuel, 450 años de historia, Santiago, Ilustre Municipalidad de Pudahuel, 2007; y Araucaria Rojas Sotoconil, Memorias de Las Barrancas y Lo Prado. Los origenes, el pasado y el presente. Rescate de la memoria lopradina desde la historia de los barrios, Santiago, Municipalidad de Lo Prado, 2012.

44 ANMI, vol. 12365, Providencias 9655-10141, Providencia $\mathrm{N}^{\circ} 10080,18 / \mathrm{julio} / 1947$ y antecedentes (denuncia de particulares, 26/marzo/1947; y oficio $\mathrm{N}^{\circ} 6285$, del Director General de Carabineros al Ministro del Interior, 13/junio/1947). Fernando Barahona Barahona fue borrado del Registro Electoral en 1948. Véase el listado íntegro en El peligro rojo, Santiago, Impresores Bustos y Letelier, 1951.
} 
ocupación de un terreno desocupado en Barrancas, y una relativamente rápida negociación que condujo a la entrega del predio en Los Nogales. ${ }^{45}$

Mientras esto ocurría, la chacra de Los Nogales estaba siendo considerada para construir allí una población. En julio de 1947 se daba cuenta de un plan en ese sentido. El Vicepresidente de la República Luis Alberto Cuevas se comprometió a levantar mil viviendas de emergencia en esa propiedad, perteneciente a la Caja del Seguro Obrero. En todo caso, todavía no se indicaba quienes serían beneficiados de esta solución habitacional de emergencia. ${ }^{46}$

La situación quedó en suspenso durante más de un año. No hubo desalojo, pero tampoco una solución definitiva. En varios momentos, de forma intermitente, prosiguieron las negociaciones entre el Comisariato, la Caja de Seguro Obrero, la Caja de la Habitación y los propietarios de la Población Gabriela Mistral (la nueva denominación que tuvo la Anexa Lautaro). Finalmente, el Seguro Obrero cedió el terreno a la Caja de la Habitación y con ello se pudo proceder a la instalación de los pobladores en Los Nogales. El traslado a la nueva ubicación se produjo el 12 de enero, pero de 1948, como lo consigna la prensa de la época. Es posible que una avanzada ya se hubiera trasladado al lugar, días antes. Como los pobladores tenían materiales acumulados, procedieron inmediatamente a construir sus casas. ${ }^{47}$ La memoria colectiva recuerda que el traslado (o la ocupación, según la versión) se produjo un día 8 de enero. Hay coincidencia en que el año de estos sucesos fue 1947, lo que hasta hoy sirve de punto de referencia para conmemorar el origen de la población. Pareciera que, de algún modo, en la memoria se fusionaron varios momentos, como si hubieran constituido un mismo acto: la ocupación de terrenos en Barrancas, en noviembre de 1946; las negociaciones para lograr una nueva asignación (durante 1947) y la entrega física de las casas en Los Nogales (un 8 o 12 de enero de 1948).

Según el relato de Vergara, el traslado dio paso a una nueva fase. La primera tarea fue decidir el nombre de la población. Se pensó primero en Gabriela Mistral, recién galardonado con el Premio Nobel, aunque finalmente se optó por el nombre tradicional del predio, Los Nogales. Vergara olvida que la primera denominación (Población Gabriela Mistral) se utilizó efectivamente, aunque ligada al emplazamiento original, en Barrancas. ${ }^{48}$ La distribución de los lotes en Los Nogales, realizada por los propios vecinos, consideró superficies de 10 por 20 metros, respetando el espacio para las veredas y las calles. ${ }^{49} \mathrm{Un}$ sitio fue reservado para el local de la comunidad, aunque su construcción se postergó por

\footnotetext{
${ }^{45}$ Vergara, "Cómo nació la idea de ocupar", pp. 1-3

${ }^{46}$ El Siglo, 9/julio/1947, p. 4.

${ }^{47} \mathrm{La}$ información indicaba que Waiss era el propietario, aunque, como vimos, su función era más bien de representación legal. La Nación, 13/enero/1948, p. 2. La referencia a la Población Gabriela Mistral aparece también en Vivienda Popular, N¹ (3ra época), 2da quincena/enero/1949, p. 2.

${ }^{48}$ La Población Anexo Lautaro se ubicaba en Santa Nora (entre San Pablo y Portales, casi al frente del actual edificio de la Municipalidad de Lo Prado), inmediatamente al poniente de la Población Lautaro. Véase, Pudahuel, p. 162; Robles, op. cit., p. 41.

${ }^{49}$ Vergara, "Cómo nació la idea de ocupar", p. 3.
} 
varios años. ${ }^{50}$ Iguales medidas se habían aplicado en Lo Zañartu y ligeramente distintas en Luis Emilio Recabarren, como veremos, lo que nos hace suponer que de algún se transmitió el esquema de distribución del espacio.

Según el testimonio de Vergara, no hubo mayor apoyo del Estado para resolver el tema del agua potable y la electricidad. Todo fue resultado de la capacidad de organización de los mismos pobladores. En su relato no hace referencia a la presencia de grupos políticos, algo que, sabemos, existió, tanto en la planificación como en las negociaciones, cuando menos en la etapa inicial. Las razones de esta omisión pueden ser varias. El propio Vergara pudo no tener un vínculo especial con estos grupos, o bien cuando redactó su texto esperaba realzar la capacidad y la autonomía de los pobladores. Por otra parte, aunque el grupo mayoritario provino de Barrancas, el gobierno instaló en el lugar a más personas (en el sector norte de la población), por ejemplo, de los conventillos de la calle Castro, totalizando 1.600 familias. ${ }^{51}$ Quizás esto colaboró a diluir la memoria de las 90 familias que fueron protagonistas de la toma original. La represión desatada a partir de 1948 pudo hacer el resto, porque seguramente obligó a la semiclandestinidad y la dispersión de los principales líderes.

En enero de 1949, a un año del traslado, Vivienda Popular describía las penosas condiciones en que vivían los habitantes de la Población Los Nogales, al contar con un solo pilón para abastecerse de agua. Por entonces, ya existía un club de fútbol que llevaba el nombre de Capitán Gálvez. Al parecer, había sido creado en octubre de $1948 .{ }^{52}$ Este capitán de la Fuerza Aérea se desempeñaba en el Departamento de la Vivienda del Comisariato, y fue designado para relacionarse con los pobladores. Una calle de la población también lo recuerda. Ercides Martínez atribuye la formación de este club a una estrategia de los comunistas para poder resistir la represión de González Videla, que por entonces se estaba agudizando. ${ }^{53}$ Posiblemente la militancia comunista de varios pobladores provocó una especial atención de la policía en Los Nogales. Además, el episodio de la toma en Barrancas no fue olvidado completamente. En enero de 1949 el proceso judicial que se había abierto por entonces estaba siendo reactivado. Cerca de cuatrocientos participantes ya habían sido citados. ${ }^{54}$

Aunque la formación de los clubes deportivos respondía a varias razones, la búsqueda de un espacio propio de encuentro se hizo más urgente en un contexto como el que surgió a

\footnotetext{
${ }^{50}$ Domingo González Núñez, “Los primeros años de la Población”, en Historia de la población Los Nogales y otros poemas, Santiago, Taller Literario Los Copihues, Vicaría de Pastoral Social del Arzobispado de Santiago, 1999, p. 31.

${ }^{51}$ El texto manuscrito plantea que en conjunto había 230 familias, aunque el número está tachado y corregido, con el número 1.600 superpuesto. En la versión impresa se incluye el dato definitivo, de 1.600 familias. Vergara, "Cómo nació la idea de ocupar", pp. 3-6; Augusto Vergara González, "Población Los Nogales", en Historia de la población Los Nogales, pp. 11-12.

${ }^{52}$ Vivienda Popular, $\mathrm{N}^{\circ} 1$ (3ra época), 2da quincena/enero/1949, p. 2.

${ }^{53}$ Martínez, "Enrique Molina Gutiérrez”, citado.

${ }^{54} \mathrm{La}$ crónica culpaba de esto a Oscar Waiss y Cortés Correa. Vivienda Popular, $\mathrm{N}^{\circ} 1$ (3ra época), 2da quincena/enero/1949, p. 2.
} 
partir de 1948. En el caso de Los Nogales hubo varios. El primero se denominó Gabriela Mistral, y se dice que fue fundado el 28 de enero de 1948. Luego vendrían, en orden de formación, los clubes Población Nogales, Capitán Gálvez y Luis Alberto Canales/Corrales. No fueron los únicos porque luego aparecieron los clubes Independiente, Ducal, 8 de Enero, Halcón de Oriente y Hermanos Carrera. ${ }^{55}$ Aunque en esta población fueron especialmente numerosos, la creación de clubes deportivos era una estrategia de organización bastante arraigada en muchos barrios. ${ }^{56}$ Algo similar ocurrió con la toma de Lo Zañartu, como veremos. ${ }^{57}$

\section{Población Zañartu}

Uno de los primeros relatos que se refiere a la toma que más adelante pasaría a ser recordada como la Población Zañartu lo conocemos por la descripción que hizo Isaías Dieguez. Este arrendatario del fundo Lo Valdivieso, de propiedad de la Caja de Seguro Obrero, se apersonó el día 4 de junio de 1947, en los alrededores del Estadio Nacional. Un grupo de "muchachotes", unos treinta, según su estimación, instalados el día anterior, le impidió el paso por medio de rechiflas, groserías y amenazas. Pudo observar que mientras unos vigilaban y controlaban el ingreso, el resto se dedicaba a levantar "ranchos de tablas". Dieguez se retiró, pero regresó horas después, ese mismo día, acompañado de carabineros. En esa ocasión, la actitud de los ocupantes cambió, adoptando un tono más argumentativo. Se negaron a abandonar el lugar pacíficamente, asegurando que eran cotizantes ("asegurados") y tenían derecho a ocupar un terreno de propiedad de la Caja. Ante tal respuesta, la policía se retiró, debido a que no tenían una orden de desalojo. En los días siguientes, Dieguez reclamó ante la Caja, la que designó un abogado para iniciar las gestiones necesarias, posiblemente judiciales o bien administrativas. Al día 18, fecha en que se publicó en El Imparcial la carta de Dieguez dirigida al Presidente de la República, todavía no había una orden específica de desalojo, lo que impedía que Carabineros se decidiera a actuar. Con el paso de los días se sumaron más ocupantes, previamente autorizados por quienes custodiaban el ingreso. A cada familia le designaban una superficie de 20 por 40 metros. El día 10 se integraron las mujeres y los niños. ${ }^{58}$ Días antes Dieguez había enviado una carta al director de El Diario Ilustrado, explicando la situación de modo similar. ${ }^{59}$

\footnotetext{
${ }^{55}$ Historia de la población Los Nogales y otros poemas, citado, pp. 18 y 39. También puede consultarse el sitio http://poblacionlosnogales.cl/la-poblacion-en-imagenes/el-deporte-en-la-poblacion/

${ }^{56} \mathrm{Al}$ respecto, véase Brenda Elsey, Citizens and sportsmen. Fútbol and politics in twentieth-century Chile, Austin, University of Texas Press, 2011.

57 En enero de 1949, el club Capitán Gálvez, de Los Nogales, desafiaba, a través del periódico Vivienda Popular, al Club Luis Gálvez, de la Población Nueva La Legua, donde residían quienes habían participado en la toma de Lo Zañartu, lo que muestra las relaciones que por entonces existían entre dos tomas de terreno de similar época. Vivienda Popular, N¹ (3ra época), 2da quincena/enero/1949, p. 2.

${ }^{58}$ El Imparcial, 18/junio/1947, p. 1.

${ }^{59}$ En este texto, fechado el 11 de junio, hay algunas variantes en la descripción de los hechos. Aunque coincide en plantear que el día 4 de junio descubrió a los ocupantes, indica que al día siguiente seguían construyendo sus ranchos, pero ya no estaban los jóvenes que le impidieron el paso, siendo reemplazados por familias con niños. El número de ocupantes (que llegaba en carretelas tiradas por caballos, con tablas,
} 
El lugar específico donde se produjeron estos hechos no nos queda claro. En el sector había actividad agrícola (estaban las viñas Santa Elena, Santa Carolina, Lo Valdivieso) y lechera. Justamente Dieguez tenía una lechería en Lo Valdivieso. Sin embargo, en las inmediaciones del Estadio Nacional, inaugurado en 1938, ya había predios loteados. En esta primera descripción de la ocupación no se habla de Lo Zañartu (o Zañartu), sino de Lo Valdivieso, denominación propia de la chacra donde se instalaron los ocupantes.

La Población Zañartu existía desde antes, en una zona cercana. En febrero, El Siglo dio tribuna a una denuncia formulada por 200 familias de compradores de sitio y medieros que, desde hacía "muchos años", estaban instalados allí, con una urbanización parcial, que solo disponía de agua a través de pilones, los que la Empresa de Agua Potable acababa de retirar. La propuesta de instalar grifos en ciertas esquinas nos permite conocer su ubicación más precisa: Zañartu con William Rebolledo, frente a la Imprenta Universo, y Rodrigo de Araya con Los Alerces, al lado poniente de una cancha. ${ }^{60}$ En planos anteriores a 1946 efectivamente se observa un incipiente trazado de calles en torno a Av. Zañartu, Los Acacios (Rodrigo de Araya) y Los Alerces. ${ }^{61}$ Además, a comienzos de 1947, la candidata comunista a regidora por Ñuñoa (Luisa Vicentini) describía la miseria y los esfuerzos de superación que pudo observar en Lo Encalada y Lo Zañartu. ${ }^{62}$

Desde 1946 la Municipalidad de Ñuñoa tenía planes de construir en la Población Zañartu, en un predio de su propiedad, habitaciones para los obreros del municipio. Esto se vio frustrado en abril de 1947, cuando se denunció que un grupo, perteneciente al Frente Nacional de la Vivienda, se había instalado en el lugar. El consejo municipal, por entonces de mayoría conservadora, decidió el desalojo de esta ocupación ilegal y de otra en la Población Sud América. La prensa hablaba de 600 familias afectadas por la orden, posiblemente en referencia a ambas localizaciones. ${ }^{63}$ Debió haber cierto apoyo o tolerancia por parte de algunas autoridades del gobierno para que se produjeran estas ocupaciones. En mayo, en el consejo municipal se lamentó que la comisión designada para ubicar a la gente sin casa siguiera "enviando pobladores a radicarse a Ñuñoa". ${ }^{4}$

La ocupación ilegal de Lo Zañartu debió haberse producido en sucesivos momentos, porque en junio se informó de una nueva ocupación, en forma casi simultánea a la ocupación de Lo Valdivieso, que ya mencionamos. El 7 de junio, Enrique Marty, socio y

herramientas y menaje) aumentaba día a día y ya superaba las cien familias. El Diario Ilustrado, 12/junio/1947, p. 5.

${ }^{60}$ El Siglo, 28/feb/1947, p. 8.

${ }^{61}$ Así se aprecia, por ejemplo, en el "Moderno y práctico Plano de Santiago”, DAK, 1939 (3ra edición).

${ }^{62}$ El Siglo, 16/marzo/1947, p. 4

${ }^{63}$ El Siglo, 24/abril/1947, p. 8; 30/abril/1947, p. 4. Sesiones del 10/abril/1947, 28/mayo/1947, 10/sept/1947 y 24/marzo/1948, en Archivo Municipalidad de Ñuñoa - Actas [Libro de Actas de Sesiones Municipales], 1946-1948, fs. 295, 329-330, 413-414, 417-418, 561

${ }^{64}$ Sesión del 28/mayo/1947, en Archivo Municipalidad de Ñuñoa - Actas, 1946-1948, f.330. La relación con el Frente Nacional de la Vivienda queda ratificada por la presencia del abogado Capdeville, en representación de los ocupantes. Véase, la sesión del 10/sept/1947, f.417-418. 
representante de Trave y Marty Ltda, empresa propietaria de un predio sin edificar ubicado en la Población Zañartu, denunció a la policía la ocupación del lugar por parte de un centenar de familias. Carabineros constató que había 160 personas, instaladas en 40 casitas de madera con barro. Se les conminó a retirarse del lugar dentro de 24 hrs, pero ellos respondieron que no tenían dónde instalarse. Finalmente el Ministerio del Interior se fijó un plazo más amplio para reubicar a los ocupantes. ${ }^{65}$ La situación ya había escalado a nivel político, y comenzaría una larga espera.

A veces, textos de la época aluden a la Población Lo Valdivieso como colindante con la Población Zañartu, como si se tratara de situaciones distintas, ${ }^{66}$ aunque en otros artículos de prensa se emplea la denominación Lo Zañartu para referirse a la población instalada en dos sectores: en un predio de la Caja del Seguro Obrero, con unas 110 familias (es decir, Lo Valdivieso) y en un sitio perteneciente a particulares, con otras $500 .^{67}$

Enrique Molina, antiguo ocupante de Lo Zañartu, aporta algunos datos sobre el origen de la toma. Unas 80 familias, en total doscientas personas, que habitaban un conventillo, ubicado en Santa Elena al llegar a Maule, tenían aviso de desalojo. Varios de ellos eran basureros, trabajadores del aseo de la Municipalidad de Santiago. Los dirigentes comunistas de la $10^{\mathbf{a}}$ comuna, que participaban del movimiento de los arrendatarios, se dieron la tarea de encauzar esta necesidad de vivienda. Lo hicieron organizando una toma de envergadura, que generara impacto, a diferencia del común de las ocupaciones, que se hacían de forma silenciosa. El plan consideró informar al alcalde de Santiago y a la esposa del presidente, la señora Markmann, que habían obtenido un terreno en arriendo (lo que era falso) y que necesitaban su ayuda para el traslado, consiguiendo algunos carretones del aseo, tirados por caballos. Eso permitió movilizar a varias familias, mientras otras lo hicieron por sus propios medios. Se decidió también que la distribución de los diferentes lotes sería regular, respetando una medida y un cierto orden, para diferenciarse del común de las tomas, dominadas por la improvisación. ${ }^{68}$

\footnotetext{
${ }^{65}$ ANMI, vol. 12342, Oficios 2657-2986, Oficio N²809, 30/junio/1947, del Ministerio del Interior a Enrique Marty Carrera, y antecedente (oficio de la Dirección General de Carabineros al Ministerio del Interior, del 24/junio/1947).

${ }^{66}$ En un artículo publicado en julio, referido a algunos incidentes en la Población Valdivieso, se habló en esos términos, como dos lugares colindantes. El Siglo, 25/julio/1947, p. 8. En otros no se mencionaba Lo Zañartu, sino solamente se aludía a Lo Valdivieso como el foco de los incidentes. El Siglo, 24/julio/1947, p. 1; 25/julio/1947, p. 3 y 5

${ }^{67}$ El Siglo, 25/julio/1947, p. 3 y 5. Un reportaje publicado en Mundo Nuevo también indicaba que una parte de la Población Zañartu estaba en un predio de la Caja de Seguro Obrero, mientras otra se ubicada en terreno de particulares. Mundo Nuevo, 8/agosto/1947. De ello inferimos que Lo Valdivieso no es una población distinta de Lo Zañartu, sino un sector específico.

${ }^{68}$ Conocemos dos relatos de Enrique Molina, que no son completamente coincidentes. En uno habla de un desalojo, y en otro de un aviso de lanzamiento, para ser efectivo en la Navidad de 1946. Los Guaracheros [Enrique Molina], “Cómo se organizó la toma de Zañartu”, en Lo que se teje en La Legua. Historia, poesía y canciones de su gente, Santiago, Eco Educación y Comunicaciones, Red de Organizaciones Sociales de La Legua, 1999, pp. 86-89. Testimonio de Enrique Molina, en Gustavo Arias y otros, Expediente técnico para la declaratoria de zona típica La Legua, s/e, s/a, pp. 27-28.
} 
Para Dieguez, todo formaba parte de un plan preconcebido: "Llama la atención el orden, disciplina y oportunidad para proceder. No hay nada entregado al azar, todo ha sido previsto: es la verdadera táctica de ocupación. Ahí hay cabeza directora y masa obediente". ${ }^{69}$ Como se puede apreciar, las sospechas apuntaban a una planificación cuasi militar, de rasgos casi conspirativos, sin real participación de la comunidad. El relato proseguía: "Esta orden, esa preparación, importa premeditación y no es espontánea, ha sido largamente preparada y estudiada en todos los detalles. Ese hecho, tiene caracteres de suma gravedad, acusan un propósito definido, cuyas consecuencias son la ocupación de los predios agrícolas cercanos a las ciudades. El caso de 'Lo Valdivieso' no es único en Santiago". ${ }^{70}$ Aunque las presunciones de Diéguez parecen exageradas (ilustrando de paso el ambiente crispado de la época), su observación resultó acertada al lograr percibir una coordinación nunca antes vista, tanto para organizar esta toma, como para relacionar iniciativas similares.

El Siglo venía siguiendo desde antes el tema de los desalojos y las condiciones miserables en que se vivía en el Zanjón de la Aguada. El 11 de junio, por primera vez, en sus páginas se mencionó la orden de lanzamiento que se pretendía aplicar a 250 familias de la Población Zañartu, cuyas viviendas son descritas como "cabañas y pocilgas", algo muy distinto a la ordenada planificación de Lo Valdivieso. Los afectados, unas mil personas, pedían amparo al Gobierno. El presidente del Comité, Humberto Andrade, relató al diario, indignado, la notificación de lanzamiento por parte del capitán de Carabineros, de la 13a comisaría, dentro de 48 horas. El policía les habría dado un ultimátum: o salían por las buenas o a la mala. La respuesta de Andrade fue tajante: "Nosotros no saldremos ni a las buenas ni a las malas". ${ }^{71}$

Al día siguiente, El Siglo modificó la cifra de ocupantes: eran 900 las familias amenazadas de desalojo en la Población Zañartu, unas 4 mil personas, distribuidas en nueve manzanas. Su solicitud era la misma: casas de emergencia, que el Gobierno había prometido en su campaña electoral. El diario destacaba el alto nivel de organización que tenían. ${ }^{72}$

El día 13 El Siglo informaba que el Intendente René Frías no autorizaría el uso de la fuerza pública para lanzar a los ocupantes de Lo Zañartu, "salvo que así lo disponga orden legal y el Gobierno". ${ }^{73}$ Por entonces, Frías enfrentaba una acusación judicial por negarse a ejecutar órdenes de lanzamiento. Se decía que había evitado el desalojo de unas 15 mil personas. ${ }^{74}$

\footnotetext{
${ }^{69}$ El Imparcial, 18/junio/1947, p. 1.

${ }^{70}$ El Imparcial, 18/junio/1947, p. 1.

${ }^{71}$ El Siglo, 11/junio/1947, p. 8.

${ }^{72}$ El Siglo, 12/junio/1947, p. 8?

${ }^{73}$ El Siglo, 13/junio/1947, p. 8.

${ }^{74}$ Lo afirmó el propio Frías. La Nación, 18/abril/1947, p. 11; 25/abril/1947, p. 8. En marzo, El Siglo calculaba que Frías había impedido más de 200 lanzamientos, cifra muy distante a la anterior si se refiriera a familias, aunque quizás implicaba cités o comunidades mayores. El Siglo, 26/marzo/1947, p. 1. Más adelante se habla de 15 mil familias, lo que parece una equivocación. El Siglo, 25/julio/1947, p. 3 y 5.
} 
A pesar de mantener su posición, en julio la comisaría más cercana hostigó particularmente a los ocupantes del sector de Lo Valdivieso, perteneciente a la Caja de Seguro Obrero. ${ }^{75}$

Si volvemos al testimonio de Molina, éste enfatizaba el orden predominante en la Población Lo Zañartu, que se parece mucho a la descripción de Dieguez, que vimos al comienzo. En algún momento, una comisión de pobladores fue a conversar con los estudiantes de arquitectura, quienes visitaron el lugar de la toma y los orientaron, con papel en mano, para planificar las calles y medir el predio de cada vivienda, con una huincha, de 10 por 20 metros cada una. ${ }^{76}$ Un modelo similar se utilizó, diez años después, en la toma de La Victoria. El plano que se tenía previsto (realizado por el equipo profesional de apoyo, de militancia comunista) contemplaba sitios de 10 por 20 metros, con un parque central y un centro cívico. Sin embargo, la necesidad de utilizar todo el espacio posible fue modificando ese proyecto y los sitios terminaron siendo reducidos a 9 por 18 , y finalmente a 8 por $16 .{ }^{77}$

Aunque los indicios son escasos, en una concentración convocada para un día domingo, se anunció la presencia del párroco de Nuñoa. Finalmente no se consignó si había asistido o no. ${ }^{78}$ No sabemos si fue un intento de los pobladores de acercarse a la Iglesia o si fue esta la que tuvo intención de visitarlos. En ese acto habló Armando Avendaño, presidente del Comité de Pobladores de la Población Lo Encalada. ${ }^{79}$

Lo Encalada era una toma ubicada al poniente del Estado Nacional. Nilo Zamora, dirigente de Lo Zañartu, la recordaba particularmente, aunque la consideraba menos organizada y más pequeña. ${ }^{80}$ Quizás haya sido así, pero a lo largo de 1947 se activó su presencia, en coordinación con Lo Zañartu y el resto de los pobladores de Ñuñoa, demandando la venta de los sitios y la construcción de viviendas de emergencia. ${ }^{81}$

Según lo recordaba años después Jaime Álvarez, el intendente visitó Lo Zañartu y ordenó a la policía suspender toda acción represiva, pero también prohibió continuar con ella, es decir, les pidió suspender el ingreso de más familias. Tras la reunión oficial se acercó a ellos y les habló de nuevo, esta vez en confianza: como autoridad había tenido que prohibir que continuara la ocupación, porque estaba en presencia de funcionarios públicos que podían informar al gobierno de su actitud, pero ellos tenían la obligación de invadir el lugar, ojalá en un par de días, para que no cupiera un alfiler. ${ }^{82}$

\footnotetext{
${ }^{75}$ El Siglo, 25/julio/1947, p. 3 y 5.

76 Testimonio de Enrique Molina, en Arias y otros, op. cit., p. 29.

77 Emanuel Giannotti, "Una ciudad de propietarios. El caso de la Población La Victoria", en $A U S, \mathrm{~N}^{\circ} 15$, 2014, pp. 40-45.

${ }^{78}$ El Siglo, 15/junio/1947, p. 12; 16/junio/1947, p. 8.

${ }^{79}$ El Siglo, 16/junio/1947, p. 8.

${ }^{80}$ Arias y otros, op. cit., pp. 28-29.

${ }^{81}$ Entre sus dirigentes se mencionaba, por entonces, a Armando Avendaño y Francisco Rojas. El Siglo, 16/marzo/1947, p. 4; 16/junio/1947, p. 8; 3/nov/1947, p. 4; 10/nov/1947, p. 8.

${ }^{82}$ Jaime Alvarez, "Historia de la Población Nueva La Legua", en Lo que se teje en La Legua, citado, pp. 102103.
} 
El 13 de junio los 450 jefes de familia se reunieron en asamblea. Ratificaron su demanda de viviendas de emergencia, para así dar cumplimiento a las promesas del gobierno en la campaña electoral. También eligieron la nueva directiva del Comité Central de la Vivienda de la Población Zañartu. En la ocasión fue elegido Efraín Gallardo. Además, se aprobó un reglamento. ${ }^{83}$ Aunque no tenemos los nombres de todos los dirigentes, los que conocemos eran todos hombres. El Comité Central agrupaba a todos los subcomités, por manzana, con sus respectivos responsables. ${ }^{84}$ Según algunos recuerdos, Luis Figueroa, futuro dirigente de la CUT, también presidió el Comité Central de la población. ${ }^{85}$. Esta estructura se replicaría en la siguiente década en el Zanjón de la Aguada, Barrancas y La Victoria. ${ }^{86}$

En octubre y noviembre de 1947, ya con los comunistas en abierta oposición al gobierno, las negociaciones se entramparon. La propiedad del sitio fue uno de los problemas difíciles de resolver. En octubre ya había una orden de desalojo judicial, producto de las denuncias presentadas por los propietarios. ${ }^{87}$ Ese mismo mes, el diario La Opinión, caracterizado por su fuerte posición anticomunista, dio tribuna a un grupo de pobladores de Lo Zañartu, miembros de un subcomité, cuyos integrantes no identificó, que habría denunciado judicialmente a los dirigentes comunistas de la toma, por el delito de estafa. Estos eran Efraín Gallardo, Enrique Molina, Arturo Carrasco, Julio Espinoza y Germán Bañados. El diario no siguió informando al respecto, lo que puede ser indicio de que el asunto no tenía fundamento o que nunca hubo tal denuncia. ${ }^{88}$ No fue primera vez que se trató de cuestionar la solvencia moral de los comunistas. ${ }^{89}$

${ }^{83}$ El Siglo, 14/junio/1947, p. 2. Sobre el cargo de Gallardo, también El Siglo, 17/junio/1947 y Alvarez, op. cit., p. 102.

${ }^{84}$ Dos de ellos eran Humberto Andrade y Samuel Aguilar Peña. El Siglo, 13/junio/1947, p. 8.

${ }^{85}$ La referencia a Luis Figueroa la hace Martínez, "Enrique Molina Gutiérrez", citado. También se lo comentó Luis Figueroa a Luis Corvalán, quien lo informó a Mario Garcés. Véase Garcés, op., cit., p. 340. Otros dirigentes fueron Arturo Carrasco Flores, el viejo Flores, el viejo Villa Toro y Enrique Molina. Véase Los Guaracheros, op. cit., p. 88. No tenemos referencias a sus cargos.

${ }^{86}$ Sobre los dos primeros casos, la referencia corresponde al año 1955, aunque seguramente estos Comités Centrales, que agrupaban a varios comités de base o locales, existían desde antes. Véase Manuel Loyola, Los pobladores de Santiago, 1952-1964: su fase de incoporación a la vida nacional. Santiago, tesis para optar al grado de Licenciatura en Historia, Pontificia Universidad Católica de Chile, 1989, p.46. El Comité Central de la Población La Victoria, que agrupó los distintos comités que participaron en la toma, tuvo su propio periódico, La Voz de La Victoria (1958-1959). Sobre la ocupación, véase La Victoria. Rescatando su historia, Santiago, Grupo de Trabajo de La Victoria, Editorial Arcis, 2007.

${ }^{87}$ La Hora, 31/oct/1947, p. 1.

${ }^{88} \mathrm{La}$ denuncia indicaba que los dirigentes habían recibido dinero para la compra del sitio, que decían era de su pertenencia (afirmación muy extraña), cuando en verdad era de propiedad de varios dueños. La Opinión, 10/oct/1947, p. 4.

${ }^{89}$ Uno de los argumentos más fuertes contra los comunistas (en prensa como La Opinión y El Diario Ilustrado) se refería a aspectos morales, debido a la supuesta utilización que estos hacían de las necesidades de las personas, cobrando cuotas y vendiendo vales de racionamiento, para mantenerlas controladas y vivir a sus expensas. El caso más bullado fue el del aceite. Este mismo patrón se replicó durante la Unidad Popular respecto de las Juntas de Abastecimiento y Precios (JAP). Véase Jorge Rojas Flores, "Desabastecimiento, control de precios y denuncia moral en los inicios de la Guerra Fría. Chile, 1946-1947”, inédito. 
Quizás para limar estas asperezas y sortear el ambiente de creciente hostilidad hacia los comunistas los pobladores comenzaron a desarrollar nuevas estrategias de acción, como fue una mayor intervención de las mujeres, las que, como vimos, no habían tenido espacio en la estructura central de representación, dominada por hombres. Durante octubre, un comité de mujeres comenzó a activarse y, al parecer, logró contactarse con la esposa de González Videla, para que intercediera. El resultado de esta gestión fue la visita del comandante Riesle a la población, por invitación de la secretaria de la Sra. Markmann. En la ocasión, las mujeres conversaron con Riesle, acompañadas de Gallardo. A raíz de esto, obtuvieron una entrevista con el Ministro del Interior, a la que también asistió el abogado, Luis Capdeville. Se programó otra reunión para la semana siguiente, esta vez con el Vicepresidente de la Caja de la Habitación, José Pistono. El protagonismo de las mujeres se reforzó con la convocatoria que hicieron ellas para que se reuniera toda la población, para así dar cuenta de las diligencias. ${ }^{90}$

En ese contexto, Erick Riesle, director del Departamento de la Vivienda del Comisariato, visitó la población el 30 de octubre. Para poder dar una solución a los ocupantes, logró que se suspendiera el lanzamiento. ${ }^{91}$ Riesle no era el único uniformado vinculado a esta toma. Con la llegada de los militares al gabinete, a fines de 1947, varias instituciones quedaron en sus manos. Por ejemplo, el Comisariato General de Subsistencias y Precios pasó a ser dirigido por el general de brigada Teófilo Gómez.

A comienzos de 1948 el periódico oficial del Frente Nacional de la Vivienda daba noticias sobre la Población Zañartu, precisando que en ella habitaban 700 familias. Por entonces, en la población se desarrollaban varias iniciativas sociales, en torno a un club deportivo, una agrupación de mujeres, una brigada excursionista (con una banda de guerra en formación) y un conjunto artístico que ofrecía veladas culturales. No solo las viviendas estaban agrupadas en manzanas, sino también se había construido un local comunitario con un proscenio. Para entonces, ya existía el ofrecimiento de ubicarlos en La Legua, solución que era aceptada por los vecinos, aunque bajo condiciones adecuadas de urbanización y traslado. El periódico hacía un llamado a mantener la serenidad, no caer en la desesperanza (posiblemente algunos habían preferido mantenerse en el lugar) y no hacer caso a los "divisionistas y traidores que pretenden desmembrarlos".92 Posiblemente ya estaba afectando la persecución a algunos dirigentes y el ambiente hostil hacia esta población que había nacido bajo la conducción comunista.

A fines de abril de 1948 se inició el traslado de los pobladores al lugar que se acordó con las autoridades, perteneciente a la Caja de Seguro Obrero. Según recuerda Jaime Álvarez, no estuvieron solos, porque antes había llegado un pequeño grupo del Zanjón de la Aguada, constituido por 38 familias. De Lo Zañartu eran 700. Más adelante se sumaron unas 28 de El Peral; unas 70 de la población Rosa Markmann y finalmente unas 370 familias de la

\footnotetext{
${ }^{90}$ La Hora, 31/oct/1947, p. 1; El Siglo, 1/nov/1947, p. 8, 2/nov/1947, p. 12.

${ }^{91}$ La Hora, 6/nov/1947, p. 4.

92 Vivienda Popular, $\mathrm{N}^{\circ} 1,19 /$ febrero/1948, p. 2.
} 
Población Sudamérica. ${ }^{93}$ Es decir, en total, según estos cálculos, la población acogió a cerca de 1.200 familias.

La prensa consignó el traslado desde Lo Zañartu, aunque solo en su etapa inicial, que incluyó las primeras cien familias. La información que entregó La Nación, por entonces, calculaba un número mayor de familias que vivía en la población Zañartu y en la llamada "Papelera". Este habrían sido 1.613, lo que significaba 12.900 personas. ${ }^{94}$

Entre los funcionarios del Comisariato que participaron del traslado estuvo el capitán Luis Gálvez, el mismo que actuó en Los Nogales. En el nuevo emplazamiento, conocido como Nueva La Legua, no hubo un acondicionamiento previo. En febrero de 1949 todavía no había luz. El Capitán Gálvez había prometido instalar alumbrado y un puesto regulador del Comisariato, pero, para entonces, todavía no se había cumplido. ${ }^{95}$ La relación con el capitán Gálvez fue cotidiana durante varios meses y, ya sea en gratitud por sus intervenciones o para protegerse de futuras represalias por la presencia comunista, se formó un club de fútbol con su nombre. Según Ercides Martínez M., el Club Deportivo Luis Gálvez fue presidido por el futuro presidente de la CUT, el comunista Luis Figueroa Mazuela, para, desde allí, proseguir con la función del Comité Central, que debió desaparecer. ${ }^{96}$ En todo caso, este club representaba la identidad del grupo que provenía de Lo Zañartu, porque los que llegaron de la Población Sud América conservaron su propio club, el Deporivo Peñarol, que había nacido mientras permanecieron en Ñuñoa. ${ }^{97}$ Nuevamente el club de fútbol cumplía una función política, dentro de una comunidad como esta. No era algo extraño, si consideramos la valoración que los comunistas le venían atribuyendo al fútbol amateur desde los años 20.

La construcción de las nuevas viviendas quedó a cargo del Departamento de la Vivienda del Comisariato. Además del capitán Gálvez, estaban el comandante Erick Riesle, el Teniente Soto y el topógrafo Carlos Faut. Los nombres de todos ellos quedaron plasmados en las calles de la población. ${ }^{98}$ Incluso se habló de darle a la población el nombre del comandante Riesle. ${ }^{99}$ No encontramos comentarios negativos sobre la acción de los militares. Al contrario, pareciera que se valoró el apoyo que brindaron. En 1949, un periódico poblacional hablaba bien de la buena disposición de Riesle para ubicar a las

\footnotetext{
93 Alvarez, op. cit., p. 103.

${ }^{94}$ La Nación, 27/abril/1948, p. 2. En El Siglo, 11/junio/1947, p. 8, se había señalado que la Población Zañartu estaba ubicada en la Papelera Santa Elena, por lo que no entendemos por qué La Nación los consideraba dos asentamientos distintos. Por otra parte, no descartamos que la cifra mencionada por La Nación haya sido atribuida a Lo Zañartu y la Papelera, cuando en verdad correspondía al total de pobladores que se pensaba trasladar, desde varios lugares.

${ }^{95}$ Vivienda Popular, N² (2da época), 1ra quincena/febrero/1949, p. 4.

96 Martínez, "Enrique Molina Gutiérrez”. El Club Deportivo Luis Gálvez de la Población Nueva Legua aparece mencionado en 1949, en Vivienda Popular, N², 1ra quincena/febrero/1949, p. 4 y 5)

${ }^{97}$ Vivienda Popular, N² (2da época), 1ra quincena/febrero/1949, p. 4.

${ }^{98}$ Arias y otros, op. cit., pp. 29-30.

${ }^{99}$ La Nación, 27/abril/1948, p. 2.
} 
familias en terrenos fiscales. Las críticas iban contra el Intendente Pacheco Sty, quien utilizaba la fuerza pública rápidamente cuando se lo solicitaban. ${ }^{100}$

Para entonces, la presencia comunista se mantuvo dentro de la población, aunque debió ajustarse a las nuevas condiciones. Algunos dirigentes fueron afectados por la represión, mientras otros tuvieron que replegarse a espacios menos visibles.

\section{La Población Luis Emilio Recabarren}

La memoria que sobrevive en la Población Recabarren, de unos pocos testigos directos y de muchos de sus descendientes, maneja más de una versión sobre el momento en que se produjo la toma. Varios hablan de 1947, otros identifican los años 1948 y 1949, y hay un caso que anticipa los hechos a 1946. Respecto a la fecha, desde hace aproximadamente una década se conmemora el 28 de julio, por algunos testimonios que recordaban ese día, aunque sin mucha certeza de que sea real. En lo que sí coinciden todos es que la ocupación se produjo en invierno, entre junio y julio. Carlos Moreno, hijo de uno de los ocupantes, reconoce que ha sido difícil identificar un día y un año precisos para conmemorar el hecho, a pesar de sus esfuerzos por dejar un registro. ${ }^{101}$

Si consideramos las noticias de prensa, a partir de junio de 1947 El Siglo comenzó a dar tribuna a los pobladores de Renca. El día 19 publicó una foto de un grupo de ellos, muchas madres con sus hijos, en representación de las 400 familias que estaban a la espera de sus viviendas. ${ }^{102} \mathrm{Al}$ día siguiente volvió a insistir sobre su situación, esta vez detallando que se trataba de una población similar a las del Mapocho o del Zanjón de la Aguada. El presidente del comité era Antonio Vega, y su secretario de prensa, Héctor Pérez. Nuevamente una foto acompañó la breve crónica, esta vez mostrando el estado de las chozas, además de los rostros de algunos personajes. ${ }^{103}$ Dos días después, el mismo diario consignaba que el comité de vivienda se denominaba La Marquesita. Su encargado de prensa, el citado Héctor Pérez, comunicaba una reunión que se estaba organizando para entregar antecedentes de la construcción de las primeras viviendas de emergencia, por parte del Gobierno, a un costado de la Estación Central. Por entonces, El Siglo estaba encabezando una campaña para acelerar la construcción de este tipo de casas, aunque su propuesta incluía hacer participar a los propios pobladores en el proceso, para así no depender de los plazos y los escasos recursos de la Caja de la Habitación. ${ }^{104}$ La denominación de este comité hace pensar que este grupo estaba ubicado en lo que después sería (o quizás ya era) la Población Luis Emilio Recabarren, porque La Marquesita

\footnotetext{
${ }^{100}$ Vivienda Popular, N² (2da época), 1ra quincena/febrero/1949, p. 2.

${ }^{101}$ Carlos Moreno, conversación 19/junio/2017; América Contreras, entrevista 24/abril/2017.Carlos Moreno, "Reseña histórica de la Recabarren", inédito.

102 El Siglo, 19/junio/1947, p. 8.

${ }^{103}$ El Siglo, 20/junio/1947, p. 8.

${ }^{104}$ El Siglo, 22/junio/1947, p. 11. El centenar de casas de la Población Gabriel González Videla (denominada así ya por entonces) comenzó a construirse entre las calles Conferencia, San Vicente y Tucapel. El Siglo, 21/junio/1947, pp. 1 y 8
} 
corresponde a una calle de la actual población y era la antigua denominación del estadio municipal de Renca, cerca de la plaza. ${ }^{105}$

Carlos Moreno, resumiendo la memoria colectiva del origen de la población, que logró recuperar a través de entrevistas informales a viejos vecinos, remonta el origen de la ocupación a la llegada de un pequeño grupo de obreros a la comuna, junto a sus familias. En búsqueda de un sitio para vivir, estos obreros pampinos y mineros de Atacama comenzaron a preguntar por algún predio. En las cercanías de la plaza de Renca había recolectores de basura (existía un basural en lo que después fue la Tenencia de Carabineros) y más al sur, areneros que recogían material del río. Varios de ellos ya estaban instalados en precarias chozas. Consultados, nadie sabía el nombre del propietario del lugar. Entonces los recién llegados habrían planteado instalarse en ese terreno y comprar el sitio. La idea prendió entre algunos areneros y recolectores, y finalmente habrían acordado proceder a la ocupación, con la ayuda de algunos carretones. En los días siguientes se les unieron familias de las poblaciones Bulnes y Nueva Matucana, al sur del Mapocho. Debido a su mayor experiencia en material sindical, los nortinos se trasformaron en los líderes del movimiento. ${ }^{106}$ El papá de Carlos Moreno fue uno de los tantos que se sumó cuando la ocupación ya estaba en marcha: su hermano era carretonero y había ayudado a los pobladores a trasladar sus enseres. Le avisó para que se integrara a la toma, lo que hizo rápidamente.

Meri (América) Contreras recuerda al pequeño grupo de familias recién llegadas del norte, unas trece, entre ellas la integrada por sus padres, Luis Contreras y María Castillo y los hijos mayores que ya habían nacido. Todas esas familias estaban unidas por una necesidad común: la vivienda propia. Sin embargo, también compartían su militancia comunista, fogueada en el norte. La iniciativa de la ocupación habría surgido de una decisión del PC local, aunque rápidamente se sumaron otras familias, como los areneros del sector, que ya vivían allí, y otros pobladores que siguieron el ejemplo. ${ }^{107}$ Entre los que se sumaron como compradores estaba Alfredo Escobar, por entonces diputado en ejercicio del PC, quien vivió en la población junto a su esposa, hasta avanzada edad. ${ }^{108}$ Otros recuerdos de quienes fueron los primeros ocupantes se conservan hasta ahora. ${ }^{109}$ Aunque no tenemos la

\footnotetext{
${ }^{105}$ La calle se denominó, por mucho tiempo, Luis Emilio Recabarren, y bajo la Dictadura de Pinochet debió cambiar a La Marquesita. Sobre el antiguo nombre del estadio, Carlos Moreno, 19/junio/2017.

106 Carlos Moreno, op. cit.

107 América Contreras, entrevista 24/abril/2017.

${ }^{108}$ Según los testimonios disponibles, Escobar no participó en la toma misma, pero se integró tempranamente como comprador de uno de los sitios. Carlos Moreno, 19/julio/2017 y 24/julio/2017. Alfredo Escobar fue detenido tras el golpe de 1973, luego debió partir al exilio, regresando años después. Falleció el 5 de enero de 1986.

${ }^{109}$ Carlos Moreno ha elaborado un listado de los primeros vecinos, que gentilmente nos facilitó. Según su indagatoria, entre ellos estaban José (¿Domingo?) Melo y Rosa Páez, padres del diputado comunista Galvarino Melo Páez. Incluye también a Marcos Acuña, recordado porque falleció atropellado por un camión que transportaba las rocas que sirvieron de defensa fluvial. Además, nos informó que hace años unos antiguos vecinos le confidenciaron que en una de las casas habría estado hospedado Luis Emilio Recabarren, lo que resulta imposible, puesto que el dirigente había fallecido en 1924. Sin embargo, estos relatos que lindan en el
} 
identificación precisa del grupo de obreros que lideró la toma, podemos suponer que incluía a Raúl Skarizza, José Aguayo, Antonio (Tuco) Vega, Héctor Pérez y Domingo Hidalgo, aunque en realidad fueron varios más los anónimos participantes, como fue el caso de las mujeres, escasamente mencionadas.

La temprana influencia comunista explicaría el nombre de la población. En noviembre de 1947, la prensa ya hablaba de los vecinos de la población Luis Emilio Recabarren. Por entonces, su principal problema era detener un remate judicial, que afectaba al propietario, Juan de Dios Morandé Vicuña, por no haber pagado las contribuciones durante treinta años. Por entonces, todavía no había servicios básicos, lo que comenzó a dificultar la situación de los nuevos vecinos. El alcalde trató de paliar la situación, prometiendo instalar un pilón más cercano, para que no tuvieran que ir a la plaza. ${ }^{110}$

Un elemento a favor, que permitió hacer más visible la acción, fue el apoyo político que tuvieron a nivel local. El alcalde de la comuna, por entonces el radical Carlos Urzúa Lacoste, respaldó la petición, tratando de interceder. Lo mismo hizo Domingo Hidalgo, por entonces regidor comunista. ${ }^{11}$ Algo similar ocurría en Lo Zañartu, en la comuna de Ñuñoa, donde los pobladores contaron con el apoyo del alcalde radical, José María Narbona, quien simpatizó con estas acciones. ${ }^{112}$

En febrero de 1948, el periódico del Frente Nacional de la Vivienda consignaba que el grupo seguía intentando no ser desalojado por quien decía ser el dueño, Juan de Dios Morandé. Para ello, contaba con el apoyo del regidor Hidalgo, además del dirigente nacional del Frente, Juvenal Gordillo, quien era de la misma comuna. Por entonces, eran 150 familias, las que, en conjunto, sumaban unas mil personas. ${ }^{113}$

En febrero de 1949, una entrevista a Alina Meléndez, dirigente del Comité de la Población Luis Emilio Recabarren, aclaró el estado de la población. El peligro de lanzamiento se había disipado con la compra del predio, con un pago inicial de 140 mil pesos, y cuotas mensuales de 20 mil, que se cancelarían colectivamente. Eso alejaba el peligro de que las familias fueran "lanzadas", como había sucedido con las poblaciones Gabriela Mistral, Sudamérica y otras (aunque, en rigor, éstas habían sido trasladadas). ${ }^{114}$ Al igual que en las restantes tomas, para entonces las mujeres habían adquirido mayor presencia en los

mito resultan muy interesantes, porque ayudan a entender cómo se fue configurando la identidad de la población.

${ }^{110}$ El Siglo, 3/nov/1947, p. 4. En la crónica de El Siglo se cita al propietario, pero de forma parcial. Su nombre completo lo conocemos a través de la escritura, citada más abajo.

${ }^{111}$ El Siglo, 20/junio/1947, p. 8; 3/nov/1947, p. 4.

112 Por lo menos Narbona colaboró con la Población Sudamérica. El Siglo, 18/junio/1947, p. 8. En cambio, el alcalde anterior, el conservador Juan de Dios Vial, era partidario del desalojo, como lo denunció El Siglo, respecto de las amenazas contra 600 familias que ocupaban sitios eriazos (no identificados). El Siglo, 30/abril/1947, p. 4.

${ }_{113}$ Vivienda Popular, №1, 19/febrero/1948, p. 3. El propietario es mencionado como Juan Morandé.

114 Vivienda Popular, N² (2da época), 1ra quincena febrero/1949, p. 3. 
comités, en parte porque la persecución política hizo más compleja la actuación pública de los hombres que habían actuado como dirigentes.

En julio de 1948 Morandé traspasó el sitio a Ladislao Lira Larraín, seguramente forzado por las deudas que tenía con Tesorería. ${ }^{115}$ En septiembre de ese mismo año, el nuevo propietario vendió el terreno, de $40 \mathrm{mil} \mathrm{m} 2$, a dos representantes de los pobladores: Raúl Skarizza Boric y José Domingo Aguayo Muñoz. ${ }^{116}$ Varios años después se produjo el traspaso de la propiedad a cada poblador. ${ }^{117}$

Según recuerda Carlos Moreno, para la organización espacial de la población se contó con la colaboración del ingeniero Germán Gárate Ossandón. No tenemos claridad cuándo se produjo la distribución definitiva, considerando que los pobladores instalaron los primeros ranchos desde los inicios de la ocupación, sin esperar el traspaso legal. Posiblemente en una primera etapa su distribución no fue lineal. Quizás a partir de la formalización del traspaso se produjo una planificación mayor de la población. Con la ayuda de Gárate, se hizo el trazado, respetando las normas municipales. Según Moreno, tomando como referencia el camino vecinal (hoy Caupolicán) se midieron cinco sitios de 10 metros de frente cada uno, y 25 de fondo (es decir, de $250 \mathrm{~m} 2$ ), y se diseñó la primera calle transversal, que llevó el nombre de Pedro Aguirre Cerda. Las restantes denominaciones habrían sido escogidas de figuras significativas que representaran los valores de la ocupación, incluidos varios comunistas, como sucedería con posterioridad en la Población La Victoria: Manuel Robles (antiguo músico nacido en Renca), Ramona Parra (comunista asesinada en enero de 1946) y Ángel Veas (el ex intendente que falleció a consecuencia de su reclusión en Pisagua). Lo mismo se hizo con las calles paralelas a Domingo Santa María, como Luis Emilio Recabarren, Nicolás Plaza y Tajamar, bordeando el río. Aunque se intentó mantener cierta regularidad en las manzanas, la dirección del cauce obligó a adaptar el trazado. En esta etapa temprana, se reservó un sitio para las actividades comunitarias, que hoy conserva la Unidad Vecinal $\mathrm{N}^{\circ} 15 .{ }^{118}$ También se reservó un sitio para el local del Partido Comunista, el cual quedó inscrito a nombre de un militante, en parte porque la organización no tenía

\footnotetext{
115 Inscripción en el Registro de Propiedades, f. 7.508, №12.451 de 1948 del Conservador de Bienes Raíces de Santiago.

${ }^{116}$ La escritura fue corregida en febrero de 1949, por errores en los deslindes. En la documentación, Raúl Skarizza Boric aparecía registrado como empleado, y José Domingo Aguayo Muñoz, como carpintero. La Inscripción en el Registro de Propiedades del Conservador de Bienes Raíces de Santiago está en f. 2837 , N5128 de 1949. Una copia nos fue facilitada.

117 Conversación con América Contreras, 8 de mayo de 2017. No tenemos claridad sobre el año del traspaso, pero el plano de la subdivisión fue recién aprobado por la Municipalidad de Renca en 1960. En 1969 el loteo fue calificado de "irregular" por el Ministerio de Vivienda y Urbanismo. A partir de entonces la oficina encargada comenzó el proceso de regularización. La escritura de propiedad del sitio de Luis Contreras, por ejemplo, fue firmada en 1971. Esto se aclara en el documento de regularización del sitio perteneciente a la Junta de Vecinos, de fecha 27 de enero de 1977, protocolizado el 6 de mayo de 1977, que nos fue facilitado.

118 Moreno, op. cit. Según este mismo testimonio, los nombres de las calles fueron cambiados durante la Dictadura de Pinochet: Ramona Parra pasó a ser Biobío; Ángel Veas se transformó en Toesca; Luis Emilio Recabarren, en La Marquesita.
} 
existencia legal. ${ }^{119}$ La construcción inicial de ambos sedes fue de adobe y varias décadas después se pudo levantar una infraestructura más sólida. ${ }^{120}$

Junto con el nacimiento de la población se creó el Club de Fútbol Domingo Hidalgo. ${ }^{121}$ El nombre hacía honor al regidor comunista que había colaborado en las negociaciones que dieron origen a la población. En enero de 1948 este dirigente fue herido con arma de fuego, mientras hablaba en una reunión deportiva. Así fue denunciado en el Congreso, en momentos en que la censura impedía divulgar estas noticias en diarios como El Siglo. ${ }^{122}$ Es posible que por esa razón el club en formación llevó su nombre. Años después, cuando la organización se integró a la Asociación de Fútbol de Renca, se decidió cambiar la denominación, transformándose en el Club Deportivo Defensor Renca, como hoy se le conoce. ${ }^{123}$ Considerando que la Asociación fue creada en 1951, fue poco el tiempo que el club mantuvo su denominación original. ${ }^{124}$

El estandarte del antiguo club tiene grabado el día y el año de su fundación, el 17 de junio de 1947. ${ }^{125}$ Aunque el recuerdo del momento en que se produjo la toma se fue borrando de la memoria colectiva, confundiendo los años de la ocupación con el momento de la compra definitiva, el estandarte parece conservar un registro de insospechada precisión. El 17 de junio no fue realmente fundado el club, porque ese día (y los siguientes) todavía existía la amenaza del desalojo. Si seguimos la noticia publicada dos días después en El Siglo, fue por entonces que los pobladores se instalaron en las cercanías del estadio. La fecha que quedó grabada en el estandarte recuerda muy probablemente el momento de la ocupación, que tan estrecha relación tuvo con el origen del club.

Aunque la historia de estas tres poblaciones siguió su curso, desde fines de 1947 se había iniciado un ciclo de repliegue en el movimiento de demandas en torno a la vivienda. A comienzos de 1948, la Población Luis Emilio Recabarren estaba en etapa de estabilización. En enero, los pobladores de Barrancas eran ubicados en su nuevo emplazamiento, en Los Nogales. En abril, se producía el traslado de Lo Zañartu a Nueva La Legua. En los años siguientes, no hubo más tomas organizadas de terreno, o por lo menos, ninguna alcanzó figuración.

\footnotetext{
119 Testimonio de Contreras, 8 de mayo y 5 de junio de 2017.

${ }^{120}$ Información aportada por Contreras, 13/junio/2017.

${ }^{121}$ Moreno, op. cit.

122 En sesión del Senado, 13/enero/1948, citado por Leonidas Aguirre Silva, Discursos parlamentarios de Pablo Neruda (1945-1948), Santiago, Editorial Antártica, 1997, p. 272.

123 Moreno, op. cit.

124 Según Peña y Lillo, la Asociación habría sido fundada el 27 de abril de 1951 y su personalidad jurídica llevaba el número 1034. Raúl Peña y Lillo Valenzuela. Historia de Renca, Renca, mimeo, 1999, s/p. Un periódico local plantea una fecha de fundación ligeramente distinta: el 24 de abril de 1951, con personalidad jurídica 0285. La Voz de Renca, N², 22/mayo/1965, p.5. Lamentablemente no logramos encontrar el respectivo decreto en el Fondo Ministerio de Justicia del Archivo Nacional.

125 José Enrique Muñoz, actual socio de Club Deportivo Defensor Renca, nos facilitó una imagen del estandarte. Comunicación del 29 de mayo de 2017.
} 
Ya desde noviembre de 1947, el Frente Nacional de la Vivienda era objeto de cuestionamientos. El gobierno y la derecha buscaban la forma de que Gordillo abandonara la representación de los pobladores en la Caja de Habitación Popular, por ser comunista. Además, se acusaba al Frente de malos manejos y de inoperante. Por entonces, se decía que se estaba cursando la cancelación de su personalidad jurídica. ${ }^{126}$ Finalmente la amenaza no se materializó y se escogió un camino distinto. En febrero de 1949 el grupo disidente, mayoritariamente socialista, recuperó la personalidad jurídica, haciéndose cargo de la organización. $^{127}$

En enero de 1948, el gobierno anunciaba que no permitiría más acciones concertadas, lideradas por comunistas, quienes habían incitado la ocupación ilegal de sitios. Aunque reconocía el drama que deberían enfrentar las familias si se aplicara un desalojo (por ello se hacían gestiones para ubicar a los ocupantes ilegales en otro lugar), no estaba dispuesto a seguir tolerando la acción comunista. Una de las medidas era responsabilizar a los propietarios particulares y a los jefes de las Cajas de Previsión para que mantuvieran los cierres reglamentarios en los predios de su propiedad o a su cargo. También debían avisar con oportunidad cuando se produjera una ocupación. ${ }^{128}$

No descartamos que, en la coyuntura electoral de 1952, o meses antes, se hayan producido algunas ocupaciones. Futuras investigaciones lo determinarán. ${ }^{129}$ Sin embargo, en lo central, habrá que esperarla llegada al gobierno de Carlos Ibáñez para observar una reactivación del ciclo de movilizaciones en torno a la vivienda, que había comenzado en 1946, en el contexto de la posguerra. En él, algunos componentes de la experiencia que hemos visto volverían a aparecer.

\section{Conclusiones}

Varios esfuerzos por reconstruir la historia de los pobladores se han restringido al acotado marco de una experiencia en particular, como lo fue La Victoria, La Legua, Nueva Matucana, Nueva la Habana, etc. Eso se justifica, en muchos sentidos, porque la vivencia particular, traducida en testimonios específicos, ha tenido esos límites, potenciada después por una identidad que ha privilegiado la construcción de una comunidad en torno a la épica de la toma. También hay estudios más amplios, que han tratado de comprender las lógicas de acción de los pobladores y del Estado en materia de vivienda.

Este último enfoque generalmente opaca la experiencia compleja y particular que involucra una ocupación ilegal de terrenos, al ponerse énfasis en las dinámicas institucionales y las

${ }^{126}$ El Siglo, 11/nov/1947, p. 8.

${ }^{127}$ La nueva directiva fue presidida por Pedro Cáceres Corvalán, socialista trotskista, ya mencionado en la pugna de 1942. Otros dirigentes fueron José Molina Castillo, José Lucero y Emilio Zapata Díaz (también socialista trotskista). Vivienda, $\mathrm{N}^{\circ} 3$, 2da. quincena/sept./1949, p. 4; Nº4, 2da. quincena/oct./1949, p.1

${ }^{128}$ La Nación, 16/enero/1948, p. 2.

${ }^{129}$ Manuel Loyola avanzó en esa dirección, comenzando su búsqueda en 1952. Véase Loyola, op. cit. 
agendas políticas del gobierno y los partidos. Por su parte, los estudios monográficos en torno a una población en particular tienden a enfocarse en la identidad y suelen ser débiles en identificar las vinculaciones entre una experiencia y otra, y en considerar la intervención de actores externos.

En la coyuntura particular de 1947, la relación entre las tres tomas que hemos estudiado (y otras más, de las cuales tenemos menos antecedentes) fue muy estrecha, en gran medida por la presencia del Partido Comunista, desde su origen. Esto se pudo detectar a partir de la información de prensa y los testimonios que se han conservado. También fue posible inferirlo por ciertos patrones comunes: gran detalle en la planificación, estructura organizacional similar (Subcomités y Comité Central), regularidad en la distribución de los sitios, preocupación por conservar un espacio para la vida comunitaria y temprana creación de clubes de fútbol, que sirvieron para sortear la represión.

Hubo también diferencias. Aunque en la época se privilegió la ocupación de predios fiscales o de la Caja de Seguro Obrero para así evitar el desalojo y exigir un tratamiento especial o poder negociar en mejores condiciones, hubo excepciones, como ocurrió con los ocupantes de la Anexa Lautaro (más tarde Gabriela Mistral) y de La Marquesita (luego Población Recabarren), ambas propiedades particulares. En Lo Zañartu y en la Anexa Lautaro los pobladores finalmente fueron trasladados a predios de la Caja, por iniciativa de la autoridad. En ellas fue gravitante la figura de los militares, quienes se encargaron de establecer la relación entre el gobierno y los pobladores, a nivel práctico. En Renca no fue necesario, porque en definitiva los ocupantes llegaron a un acuerdo de compra con el propietario. En los tres casos se evitó el desalojo por decisión del Intendente Frías, ya conocido por su posición al respecto.

La identidad como grupo fue importante en las tres poblaciones, aunque mayor en la toma de Renca, en parte porque permanecieron en el mismo lugar, sin necesidad de incorporar pobladores de otro origen. En Lo Zañartu y Anexa Lautaro la situación fue distinta, ya que los ocupantes fueron trasladados a otras ubicaciones, hacia donde también convergieron pobladores provenientes de otras localidades. De hecho, las dudas sobre el origen subsisten en Los Nogales, entre quienes plantean que la toma es un mito y los que insisten en el loteo; y en La Legua la identidad de los antiguos ocupantes del campamento en Lo Zañartu quedó subordinada a la historia de la propia Población La Legua, que ya existía y siguió constituyéndose en los años siguientes, por grupos de variado origen.

El relativo desconocimiento de las tomas que surgieron en el período 1945-1947 (así como de la agitación campesina, que se desató en forma casi paralela) puede tener varias explicaciones. La más convincente parece ser el contexto de persecución que surgió en los años siguientes, que llevó a prestar atención a otros temas. La historiografía social heredó esta circunstancia y no ha estudiado, hasta ahora, el ambiente de convulsión que antecedió a la proscripción comunista. 
Las tres ocupaciones que hemos estudiado no fueron las únicas. Junto a otras que apenas hemos mencionado, y que futuros investigadores quizás puedan llegar a conocer más en detalle, las tomas constituyeron una expresión visible y evidente del ambiente de descontento y de demanda social que estaba surgiendo en respuesta a las débiles políticas de vivienda. Demostraron la capacidad de organización, coordinación y planificación de los grupos que tomaron el liderazgo y asumieron un rol activo de conducción. No pocos cambios institucionales (como la organización del primer censo de vivienda en abril de 1952 y la creación de la Corvi en 1953) se gestaron a partir del impacto político (siempre mediado por la prensa) que provocaron estas sucesivas acciones, por el simbolismo que transmitían y el dramatismo que generaba ver a miles de familias, siempre acompañadas de muchos niños, expuestas a precarias condiciones de vida, para obtener así una vivienda.

Al enfocarnos en estas tres ocupaciones fue posible, además, confrontar las versiones que todavía circulan sobre el momento, las circunstancias y los protagonistas que dieron origen a estas poblaciones, a partir de la memoria sobreviviente, y la secuencia de hechos que se devela a través de la prensa y la información de archivo, descubriendo relaciones entre ambos relatos. Así, pudimos llegar a entender las circunstancias específicas que dieron lugar a una peculiar memoria colectiva, a veces distorsionada y selectiva, pero siempre vívida y efectiva en reproducir la identidad de un grupo de pobladores, mantenida por sus descendientes, que debió enfrentar difíciles condiciones para lograr su objetivo de asegurar un lugar propio en la ciudad.

\section{Fuentes Consultadas}

Libros y tesis:

Aguirre Silva, Leonidas, Discursos parlamentarios de Pablo Neruda (1945-1948), Santiago, Editorial Antártica, 1997.

Elsey, Brenda, Citizens and sportsmen. Fútbol and politics in twentieth-century Chile, Austin, University of Texas Press, 2011.

El peligro rojo, Santiago, Impresores Bustos y Letelier, 1951.

Espinoza, Vicente, Para una historia de los pobres de la ciudad, Santiago, Sur Ediciones, 1988.

Farías Antognini, Ana María, Urbanización, política de vivienda y pobladores organizados en Las Barrancas: el caso de la Población Neptuno, 1959-1968, Santiago, memoria para optar al grado de Licenciado en Historia, Pontificia Universidad Católica de Chile, 1992.

Fauré, Daniel, y Cristina Moyano (eds.), Memoria social de la población Los Nogales (1947-2015), Santiago, Universidad de Santiago de Chile, 2016.

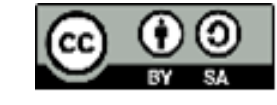


Fonseca, Ricardo, Plan inmediato de gobierno del Partido Comunista. Conferencia Nacional, octubre de 1946, Santiago, Comisión Nacional de Educación, Prensa y Propaganda del Partido Comunista de Chile, 1946.

Garcés, Mario, Tomando su sitio. El movimiento de pobladores de Santiago, 1957-1970, Santiago, Lom Ediciones, 2002.

Historia de la población Los Nogales y otros poemas, Santiago, Taller Literario Los Copihues, Vicaría de Pastoral Social del Arzobispado de Santiago, 1999.

La Victoria. Rescatando su historia, Santiago, Editorial Arcis, Grupo de Trabajo de La Victoria, 2007.

Loyola, Manuel, Los pobladores de Santiago, 1952-1964: su fase de incoporación a la vida nacional, Santiago, tesis para optar al grado de Licenciatura en Historia, Pontificia Universidad Católica de Chile, 1989.

Pudahuel: en el camino de la memoria. De las Barrancas a Pudahuel, 450 años de historia, Santiago, Ilustre Municipalidad de Pudahuel, 2007.

Robles, Marcelo, Historia de los pobladores de Las Barrancas: autonomía, participación política, politización, ideologización, resistencia y desobediencia civil de la organización de los pobladores de Las Barrancas, Santiago, tesis para optar al grado de Licenciatura en Historia, Universidad Arcis, 2007.

Rojas Sotoconil, Araucaria, Memorias de Las Barrancas y Lo Prado. Los origenes, el pasado y el presente. Rescate de la memoria lopradina desde la historia de los barrios, Santiago, Municipalidad de Lo Prado, 2012.

Sepúlveda Guzmán, Sara, Población Callampa (estudio realizado en la población callampa Nueva Matucana), memoria de prueba para optar al título de Asistente Social, Escuela de Servicio Social, Universidad de Chile, 1952.

Urrutia, Cecilia, Historia de las poblaciones callampas, Santiago, Editorial Quimantú, 1972.

Valenzuela, Humberto, Historia del movimiento obrero chileno, Santiago, Editorial Quimantú, 2008.

Artículos de revistas y capítulos de libros:

Alvarez, Jaime, "Historia de la Población Nueva La Legua", en Lo que se teje en La Legua. Historia, poesía y canciones de su gente, Santiago, Eco Educación y Comunicaciones, Red de Organizaciones Sociales de La Legua, 1999 (también en La Población La Legua desde la historia oral hacia la historia local. Santiago, ECO Educación y Comunicación, 2010).

Giannotti, Emanuel, "Una ciudad de propietarios. El caso de la Población La Victoria", en AUS, $\mathrm{N}^{\circ}$ 15, 2014, pp. 40-45 
González Núñez, Domingo, “Los primeros años de la Población”, en Historia de la población Los Nogales y otros poemas, Santiago, Taller Literario Los Copihues, Vicaría de Pastoral Social del Arzobispado de Santiago, 1999.

Los Guaracheros [Enrique Molina], "Cómo se organizó la toma de Zañartu", en Lo que se teje en La Legua. Historia, poesía y canciones de su gente, Santiago, Eco - Educación y Comunicaciones, Red de Organizaciones Sociales de La Legua, 1999, pp. 86-89 (también en La Población La Legua desde la historia oral hacia la historia local. Santiago: ECO Educación y Comunicación, 2010).

Vergara González, Augusto, "Población Los Nogales", en Historia de la población Los Nogales y otros poemas, Santiago, Taller Literario Los Copihues, Vicaría de Pastoral Social del Arzobispado de Santiago, 1999.

Publicaciones periódicas:

Acción Comunal, 1936-1937.

El Diario Ilustrado, 1946-1947.

El Imparcial, 1946-1947.

El Mercurio, 1946-1947

El Siglo, 1945-1947.

Estanquero, 1946-1952.

Habitación, 1933-1936.

La Hora, 1946-1947.

La Nación, 1946-1947.

La Voz de Renca, 1965.

Las Noticias de Última Hora, 1946-1947.

Las Noticias Gráficas, 1946-1947.

Mundo Nuevo, 1946.

Vivienda, 1949.

Vivienda Popular, 1949.

Archivos:

Archivo Nacional - Ministerio de Justicia y Ministerio del Interior

Archivo Municipalidad de Ñuñoa - Actas [Libro de Actas de Sesiones Municipales], 1946-1948.

Textos inéditos:

Arias, Gustavo, y otros, Expediente técnico para la declaratoria de zona típica La Legua, s/e, s/a, disponible en:

https://issuu.com/werkenmedios/docs/expediente_legua_versi_n_final_ago

Moreno, Carlos, "Reseña histórica de la Recabarren”, artículo inédito.

Palma Alvarado, Daniel, "Villa Olímpica, Santiago: apuntes para su historia”, artículo inédito.

Peña y Lillo Valenzuela, Raúl, Historia de Renca, Renca, mimeo, 1999. 
Rojas Flores, Jorge, "Designación de autoridades en un contexto de Guerra Fría. El caso del gobierno de Gabriel González Videla, 1946-1947”, artículo inédito.

Rojas Flores, Jorge, "Desabastecimiento, control de precios y denuncia moral en los inicios de la Guerra Fría. Chile, 1946-1947”, artículo inédito.

Rojas Flores, Jorge, "Los comunistas en el gobierno de Gabriel González Videla, 1946-1947: estrategias de acción”, artículo inédito.

Vergara, Augusto, "Cómo nació la idea de la ocupación de terrenos en las poblaciones Lautaro San Pablo, el año 45 al 46, para establecerse definitivamente en Población Los Nogales”, artículo inédito, disponible en http://poblacionlosnogales.cl/relatos-nogalinos/

Textos electrónicos:

Martínez, Arcides, "Enrique Molina Gutiérrez", en:

http://elboletinrojo.blogspot.cl/2014/12/enrique-molina-gutierrez.html.

Sitio web:

http://poblacionlosnogales.cl

Entrevistas:

Contreras, América (Meri), 24/abril/2017.

Moreno, Carlos, 19/junio/2017

Muñoz, Juan Enrique, 29/mayo/2017. 